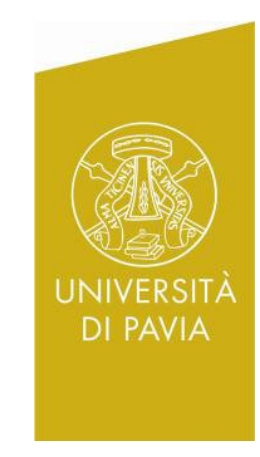

Department of Economics and Management DEM Working Paper Series

\title{
New-Keynesian Phillips Curve with Bertrand Competition and Endogenous Entry
}

\author{
Federico Etro \\ (Università di Venezia, Ca’ Foscari) \\ Lorenza Rossi \\ (Università di Pavia) \\ \# 79 (06-14) \\ Via San Felice, 5 \\ I-27100 Pavia \\ http://epmq.unipv.eu/site/home.html
}

June 2014 


\title{
New-Keynesian Phillips Curve with Bertrand Competition and Endogenous Entry
}

\author{
Federico Etro and Lorenza Rossi* \\ Ca' Foscari University of Venice and University of Pavia \\ JEL Classification: E3, E4, E5 \\ Key Words: New Keynesian Phillips Curve, Real rigidities, Sticky prices, Optimal monetary policy, \\ Inflation, Endogenous entry
}

\begin{abstract}
We derive a New Keynesian Phillips Curve under Calvo staggered pricing and price competition. Firms strategic interactions induce price adjusters to change their prices less when there are more firms that do not adjust. This reduces the slope of the Phillips curve and generates an additional source of real rigidity that magnifies the impact of monetary shocks on the economic activity. Endogenous entry amplifies the impact of both monetary and real shocks. We study the design of the optimal Taylor rule in the case of a fixed number of firms and we characterize the optimal monetary policy to restore the social planner allocation and the optimal Ramsey steady state in the case of endogenous entry.
\end{abstract}

${ }^{*}$ We are grateful to Pierpaolo Benigno, Paolo Bertoletti, Fabio Ghironi and Ester Faia for comments. Correspondence. Lorenza Rossi: Dept. of Economics and Management, University of Pavia, Via San Felice, 5, I-27100 Pavia, Italy, email: lorenza.rossi@unipv.it. Federico Etro: Dept. of Economics, University of Venice Ca' Foscari, Sestiere Cannaregio, 30121, Fond.ta S.Giobbe 873, Venice, Italy. Tel: +39-0412349172, email: federico.etro@unive.it. 


\section{Introduction}

The core idea of Keynesian economics is that in the presence of nominal price rigidities aggregate demand shocks have an impact on the real variables at least in the short run. The workhorse New Keynesian (NK) model has formalized this idea in dynamic stochastic general equilibrium (DSGE) models assuming monopolistic competition between a given number of firms in each sector and some form of price staggering. The most common form of nominal rigidity is the one introduced by Calvo (1983), in which each firm has the chance of adjusting its price with a fixed probability in each period. ${ }^{1}$ Firms re-optimize taking into account future changes in their marginal cost, which delivers the link between real and nominal variables. One of the main drawbacks of this framework is that when prices change frequently (for example every 4-6 months), nominal rigidity by itself does not suffice to explain the low slope of the New Keynesian Phillips Curve (NKPC) in estimated DSGE models, such as the one of Smets and Wouters (2003). Reconciling the micro evidence of frequently price change with the macro-evidence of a low slope of the NKPC is still a theoretical challenge of the literature that requires additional forms of real rigidities.

A second drawback comes from the fact that assuming monopolistic competition, price adjusters take as given the current and future price levels and the number of firms, ignoring any strategic interaction with the current and future competitors. This is unrealistic when local markets include a small, and possibly, endogenous number of firms producing highly substitutable goods. A large body of empirical evidence in industrial organization (Campbell and Hopenhayn, 2005), trade (Feenstra and Weinstein, 2010) and macroeconomics (see the discussion in Rotemberg and Woodford, 2000 and Faia, 2012) suggests that common markets are characterized by relevant competition effects due to imperfect competition.

Having in mind these two drawbacks, we depart from the standard model with a continuum of firms and consider a small number of direct competitors producing imperfectly substitute goods in each different market: firms take into account strategic interactions with firms in their own market, not in other markets. Our contribution to the NK literature is twofold. First, to disentangle the role played by strategic interaction, we derive a modified NKPC under Calvo pricing and Bertrand competition among a fixed number of firms. ${ }^{2}$ We find that, in line with the evidence, the modified NKPC is characterized by a lower slope than the one implied by the standard monopolistic competition model. Since strategic interactions imply that firms are less prone to adjust their prices in response to shocks, the semi-elasticity of inflation with respect to real marginal costs is much lower than in the standard NK-DSGE model. Given the direct relationship between real marginal costs and the output gap this implies that also the semi-elasticity of inflation with respect to output is lower. In particular, the slope of the modified NKPC decreases in the level of concentration of the markets and in the inter-sectoral elasticity of substitution between goods. This implies that, ceteris paribus, a higher frequency of price change is needed. In this respect, we consider our framework as a solution to partially overcome the first drawback mentioned above. Indeed, thanks to the lower slope of the NKPC, our model contributes to reconcile the micro-evidence of frequent price adjustments (Bils and Klenow, 2004; Nakamura and Steinsson, 2008) with the macroeconomic data indicating that inflation is rather inertial (see Altig et al., 2011). Furthermore, the lower slope of the Phillips curve implies that adopting a standard Taylor rule, the determinacy region enlarges as the number of firms or the elasticity of substitution between goods

\footnotetext{
${ }^{1}$ See Yun (1996), King and Wolman (1996) and Woodford (2003).

${ }^{2}$ As well known, the alternative microfoundation of nominal rigidities advanced by Taylor (1979) relies on prices predetermined for a fixed number of periods. In principle Bertrand competition between a fraction of price-setting firms would lead to the same qualitative implications as those obtained under Calvo pricing.
} 
decrease, thus admitting more accommodative rules than the standard model.

As long as the number of firms is exogenous, the distortions remain the same as in the standard NK model, with Bertrand markups higher than the monopolistic competition markups. Therefore usual results on the optimal monetary policy hold. Introducing shocks, we can also derive the optimal interest rate rule that minimizes the microfounded central bank loss function (as in Rotemberg and Woodford, 1997). The optimal interest rate rule becomes less aggressive in response to an inflationary cost-push shocks when markets are more concentrated or the elasticity of substitution between goods decreases.

Our second contribution is to endogenize the evolution of the number of firms active in these markets (following the recent literature on entry: Bilbiie et al., 2008, 2012, 2014; Etro and Colciago, 2010; Faia, 2012). We find that the impact of shocks is much stronger when taking into account endogenous business creation, but high substitutability between goods and high inter-sectoral concentration are essential for strategic interactions to amplify monetary shocks. On one side, the process of endogenous entry magnifies the effect of technology shocks by attracting more entry and strengthening competition, which in turn promotes consumption and labor supply and induces a hump-shaped pattern of inflation. On the other side, in front of an expansionary monetary shock both the real rigidities due to strategic interactions and the gradual creation of new differentiated varieties contribute to stabilize inflation so as to magnify the real effects. Importantly, a key difference between the model with monopolistic competition and the one with Bertrand competition and endogenous entry, is that the interest rate cut induces business destruction in the former and business creation in the latter, thus our model being more in accordance with the evidence. As a result, the presence of strategic interactions strongly magnifies the impact of the monetary shock on output.

Finally, we characterize the social planner problem and the required inflation rate and fiscal tools necessary to restore the efficient allocation, and we follow the methodology proposed by Schmidt-Grohe and Uribe (2011) to derive the optimal Ramsey steady state inflation in the absence of fiscal tools. With respect to the social planner allocation we find that the optimal policy requires zero PPI inflation associated with a countercyclical CPI inflation (as in Bilbiie et al., 2008), a countercyclical labor subsidy and a dividend tak which usually also countercyclical to eliminate the distortions associated with Bertrand competition that depend on the number of firms active in each period. With respect to the Ramsey problem state we find that the optimal steady state inflation rate is zero in the absence of fiscal tools. This result confirms what found under Rotemberg pricing end endogenous entry by Faia (2012). ${ }^{3}$

Other works, at least since Ball and Romer (1990), have already stressed the role of strategic complementarities between firms' prices as a source of real rigidities (see Nakamura and Steinsson, 2013, for a survey), but we are not aware of any formalization of Bertrand competition with price staggering as the natural source of strategic complementarities. A first approach to microfound real rigidities, due to Basu (1995), relies on the fact that each firm employs all the other goods as intermediate inputs, a second one, adopted by Woodford (2003) or Altig et al. (2011), relies on firm-specific inputs: in both cases marginal costs depend on firms' own relative prices, so as to generate optimal prices increasing in the price index. A third approach, advanced by Kimball (1995), relies on a demand elasticity that is increasing in the relative price, generating again strategic complementarity between prices. Recent applications of this approach by Dotsey and King (2005), Levin et al. (2007) and Sbordone (2007) have been based on a generalization of the Dixit-Stiglitz aggregator to obtain

${ }^{3}$ See also Bilbiie et al. (2014) on monopolistic competition with different homothetic preferences. 
elasticities increasing in prices and in the number of goods, but ignoring strategic interactions between price-setters. ${ }^{4}$

The recent research on dynamic entry has been mostly focused on standard monopolistic competition (Bilbiie et al., 2008, 2012, 2014). Strategic interactions and Bertrand competition have been explicitly introduced in a flexible price model by Etro and Colciago (2010), and the first applications of Bertrand competition in the NK framework have been developed by Faia (2012) to analyze the Ramsey problem of choosing the optimal state contingent inflation tax rates and by Lewis and Poilly (2012) for estimation purposes. ${ }^{5}$ However, all these models neglect price staggering and adopt a price adjustment cost à la Rotemberg (1982), which implies that all firms (rather than a fraction of them) adjust prices simultaneously and identically in each period. ${ }^{6}$ Introducing time-dependent staggered pricing à la Calvo we obtain a different form of real rigidity associated with the substitutability between goods: if few firms in a market do not change prices after a cost shock, the price adjustment of the others are smaller the more substitutable are the goods. Contrary to this, Rotemberg pricing delivers higher adjustments when substitutability increases, both under monopolistic and Bertrand competition. ${ }^{7}$

The paper is organized as follows. Section 2 presents the DSGE model with Bertrand Competition and a fixed number of firms. It shows the modified NKPC and the main results on the model dynamics and the optimal monetary policy. Section 3 endogenizes the evolution of the number of firms active in the markets and discuss the main results in the presence of endogenous market structure. Section 4 concludes.

\section{Nominal Rigidities with Bertrand Competition}

In this section we introduce Bertrand competition in a DSGE model with price staggering. Consider a representative household with utility:

$$
U_{0}=E_{0} \sum_{t=0}^{\infty} \beta^{t}\left\{\int_{0}^{1} \log C_{\iota t} d \iota-\frac{v L_{t}^{1+\phi}}{1+\phi}\right\} \quad v, \phi \geq 0
$$

where $\beta \in(0,1)$ is the discount factor, $L_{t}$ is labor supply and $E_{t}[\cdot]$ is the expectation operator at time $t$. Here $C_{\iota t}$ represents the Dixit-Stiglitz consumption index for a continuum of sectors $\iota \in[0,1]:$

$$
C_{\iota t}=\left[\sum_{j=1}^{n_{t}} C_{\iota t}(j)^{\frac{\theta-1}{\theta}}\right]^{\frac{\theta}{\theta-1}}
$$

where $n_{t} \in[2, \infty)$ is the number of producers of differentiated varieties in each sector and the price index is $P_{\iota t}=\left[\sum_{j=1}^{n_{t}} p_{\iota t}(j)^{1-\theta}\right]^{1 /(1-\theta)}$. Substitutability between goods is low across sectors (namely unitary given the log utility) but high within sectors, and each sector is highly

\footnotetext{
${ }^{4}$ Bergin and Feenstra (2000) have replaced CES preferences with translog preferences, that are homothetic and deliver an elasticity of demand increasing in a (finite) number of goods. Nevertheless, they focus on different issues and, again, thy neglect the role of strategic interactions.

${ }^{5}$ See also Cecioni (2010) for an empirical assessment of the Bertrand model and Benigno and Faia (2010) on open economy issues.

${ }^{6}$ See also Auray et al. (2012). Cavallari (2013) has adopted Calvo pricing but focusing on monopolistic competition and ignoring strategic interactions.

${ }^{7}$ Notice that the empirical analysis of Lewis and Poilly (2012) has found a small competition effect in their model with Rotember pricing, but this is not surprising since, besides various differences between setups, they have focused on a relatively high number of firms and low inter-sectoral substitutability.
} 
concentrated. The household maximizes (1) choosing how much to work and how much to consume in each period and sector, under the following budget constraint in nominal terms:

$$
B_{t}+\int_{0}^{1} P_{\iota t} C_{\iota t} d \iota=\left(1+i_{t-1}\right) B_{t-1}+W_{t} L_{t}+D_{t}
$$

where $B_{t}$ are nominal risk-free bonds, purchased at time $t$ and maturing at time $t+1$. We defined $i_{t}$ as the nominal interest rate on the risk-free bonds agreed at time $t$, while $W_{t}$ are nominal wages. Since as usual households own the firms, they receive an additional income coming from nominal profits, that are entirely distributed in form of dividends, $D_{t}$. In each period $t$ the optimality condition for consumption across sectors requires the same expenditure $I_{t}=P_{\iota t} C_{\iota t}$ for any $\iota$. Symmetry between sectors will allow us to consider a representative sector with consumption $C_{t}$ and (average) price index $P_{t}$.

Given the nominal wage $W_{t}$, the optimal labor supply is:

$$
L_{t}=\left(\frac{W_{t}}{v P_{t} C_{t}}\right)^{1 / \phi}
$$

Each firm $i$ produces a good with a linear production function. Labor is the only input, and output of firm $i$ is:

$$
y_{t}(i)=A_{t} l_{t}(i)
$$

where $A_{t}$ is total factor productivity at time $t$, and $l_{i t}$ is total labor hours employed by firm $i$. This implies that the real marginal costs in aggregate terms are $m c_{t}=w_{t} / A_{t}$, where we define the real wage as $w_{t}=W_{t} / P_{t}$. The Euler equation is:

$$
\left(P_{t} C_{t}\right)^{-1}=\beta E_{t}\left[\left(1+i_{t}\right)\left(P_{t+1} C_{t+1}\right)^{-1}\right]
$$

where $i_{t}$ is the nominal interest rate. Loglinearizing the above equations around the zero inflation steady state, we have:

$$
\begin{aligned}
\hat{w}_{t} & =\hat{C}_{t}+\phi \hat{L}_{t}=\hat{A}_{t}+\widehat{m c}_{t} \\
\hat{C}_{t} & =\hat{A}_{t}+\hat{L}_{t} \\
\hat{C}_{t} & =E_{t} \hat{C}_{t+1}-\left(\hat{\imath}_{t}-E_{t} \pi_{t+1}\right)
\end{aligned}
$$

where $\hat{\imath}_{t} \equiv \log i_{t}-\log (1 / \beta)$ is the log-deviation of the nominal interest rate from its steady state value, $E_{t} \pi_{t+1} \equiv P_{t+1} / P_{t}-1$ is expected inflation and $\hat{A}_{t}$ is the log-deviation of productivity, which will evolve exogenously following a standard $\operatorname{AR}(1)$ process $\hat{A}_{t}=\rho_{a} \hat{A}_{t-1}+\varepsilon_{a, t}$ where $\rho_{a} \in[0,1)$ and $\varepsilon_{a, t}$ is a white noise.

\subsection{Calvo pricing}

In this section we start by assuming that the number of firms active in each sector is exogenous and constant, namely $n_{t}=n$ for any $t$ (in the next section we will endogenize the number of firms). In each period, a fraction $\lambda$ of the firms across all sectors cannot adjust the nominal price and maintains its pre-determined price, and a fraction $1-\lambda$ can reoptimize the nominal price at the new level $p_{t}$, which maximizes the discounted value of future profits. Applying the law of large numbers, the average price index across all sectors in the economy is:

$$
P_{t}=\left[\lambda P_{t-1}^{1-\theta}+(1-\lambda) n p_{t}^{1-\theta}\right]^{\frac{1}{1-\theta}}
$$


whose steady state version implies $P^{1-\theta}=n p^{1-\theta}$. The usual log-linearization around a zero inflation steady state provides the average inflation rate $\pi_{t}=(1-\lambda)\left(\hat{p}_{t}-\hat{P}_{t-1}\right)$. In every period $t$, each optimizing firm $i$ chooses the new price $p_{t}$ to maximize the expected profits until the next adjustment, taking into account the probability that there will be a new adjustment $\lambda$ :

$$
\max _{p_{t}} E_{t} \sum_{k=0}^{\infty}(\lambda \beta)^{k} \frac{\left(p_{t}-\frac{W_{t+k}}{A_{t+k}}\right) p_{t}^{-\theta} I_{t}}{\sum_{j=1}^{n} p_{t+k}(j)^{1-\theta}}
$$

where the prices of the intersectoral competitors in the initial period and in all the future periods are taken as given. The FOC of this problem, after simplifying and imposing symmetry of all the adjusted prices reduces to:

$$
p_{t} E_{t} \sum_{k=0}^{\infty} \frac{(\lambda \beta)^{k}}{P_{t+k}^{1-\theta}}-\theta E_{t} \sum_{k=0}^{\infty} \frac{(\lambda \beta)^{k}\left(p_{t}-\frac{W_{t+k}}{A_{t+k}}\right)}{P_{t+k}^{1-\theta}}=(1-\theta) p_{t}^{1-\theta} E_{t} \sum_{k=0}^{\infty} \frac{(\lambda \beta)^{k}\left(p_{t}-\frac{W_{t+k}}{A_{t+k}}\right)}{P_{t+k}^{2(1-\theta)}}
$$

Loglinearizing we obtain:

$$
a_{0} \hat{p}_{t} \sum_{k=0}^{\infty}(\lambda \beta)^{k}+a_{1} E_{t} \sum_{k=0}^{\infty}(\lambda \beta)^{k} \widehat{P}_{t+k}+a_{2} E_{t} \sum_{k=0}^{\infty}(\lambda \beta)^{k}\left(\widehat{W}_{t+k}-\widehat{A}_{t+k}\right)=0
$$

where the coefficients $a_{0}, a_{1}$ and $a_{2}$ are derived in the Appendix as functions of the steady state variables. Replacing them and $\widehat{m c}_{t+k}=\widehat{W}_{t+k}-\widehat{A}_{t+k}-\widehat{P}_{t+k}$, and solving for $\hat{p}_{t}$ in a recursive form we have:

$$
\hat{p}_{t}=(1-\lambda \beta) \widehat{P}_{t}+\frac{(1-\lambda \beta)(n-1)[\theta(n-1)+1]}{[\theta-1+\theta n(n-1)]} \widehat{m c}_{t}+\lambda \beta E_{t} \hat{p}_{t+1}
$$

which can be combined with the earlier expression for inflation to obtain:

$$
\pi_{t}=\beta E_{t} \pi_{t+1}+\frac{(1-\lambda)(1-\lambda \beta)(n-1)[\theta(n-1)+1]}{\lambda[\theta-1+\theta n(n-1)]} \widehat{m c}_{t}
$$

The strategic interactions affect the way in which changes in real marginal costs are translated into price changes within sectors and therefore into aggregate inflation. As it will be clear below strategics interaction lower the slope of the NKPC.

\subsection{The modified New Keynesian Phillips Curve}

We rewrite the NKPC in terms of output gap from the flexible-price equilibrium output, given by $\widehat{y}_{t}^{*}=\widehat{A}_{t}$, the same as in the standard NK model. Thus, defining the output gap as the deviation of actual output from the flexible price equilibrium output as $x_{t} \equiv \widehat{y}_{t}-\widehat{A}_{t}$, and using the equation of the labor market equilibrium, that is $\widehat{m c}_{t}=(1+\phi) \hat{L}_{t}=(1+\phi) x_{t}$, we finally get the modified NKPC, that we augment with a supply shock: ${ }^{8}$

$$
\pi_{t}=\beta E_{t} \pi_{t+1}+\kappa(\theta, n) x_{t}+\xi_{t}
$$

where $\xi_{t}=\rho_{\xi} \xi_{t-1}+\varepsilon_{\xi, t}$ is an exogenous $\operatorname{AR}(1)$ shock with $\rho_{\xi} \in[0,1)$ and $\varepsilon_{\xi, t}$ white noise. The coefficient of the output gap is:

\footnotetext{
${ }^{8}$ As usual, the model is log-linearized around the zero inflation deterministic steady state.
} 


$$
\kappa(\theta, n) \equiv \frac{\bar{\kappa}(n-1)[\theta(n-1)+1]}{\lambda[\theta-1+\theta n(n-1)]}
$$

where $\bar{\kappa} \equiv(1-\lambda)(1-\lambda \beta)(1+\phi) / \lambda$ is the traditional coefficient under monopolistic competition. First of all, notice that the modified coefficient coincides with the traditional one in two cases: for $n$ arbitrarily large, since we are back to the case in which each firm is negligible in its own market, and when $\theta \rightarrow 1$, since firms tend to produce independent goods and strategic interactions disappear even between few firms. In all the other cases, the slope of the NKPC is smaller than the standard one and, at most, it becomes a third of it in case of two firms. This reduces drastically the impact of the output gap on inflation, a result which is desirable from an empirical point of view since, as known in the literature, the basic NKPC implies an excessive reaction of inflation to changes in real marginal costs. Usual estimates from macrodata for the coefficient of the NKPC on the marginal cost range between 0.03 and 0.05 (as for example in Levin et al. 2007). The standard model with monopolistic competition with $\lambda=0.67$ (price adjustments every 3 quarters) generates a coefficient on the marginal cost change equal to 0.166 , but this does not fit with the mentioned macroevidence on the small reaction of inflation to changes in marginal costs. Instead, Bertrand competition generates a smaller coefficient, with a lower bound of 0.055 , which is much closer to the macroevidence, mentioned above. ${ }^{9}$

Recently, Altig et al. (2011) have estimated a coefficient as low as 0.014. To look things from a microeconomic perspective, consider that with the parameter estimated by Altig et al. (2011), the standard Calvo model under monopolistic competition requires a value of $\lambda=0.9$, assuming $\beta=0.99$. This implies that prices adjust on average every 30 months, much more than what appears to be reasonable. ${ }^{10}$ The introduction of strategic interactions reduces the implied degree of nominal frictions up to $\lambda=0.82$, which implies price adjustments on average every 5.8 quarters: thus, it almost halves the average period of price adjustment, being more in accordance with the micro evidence: Bils and Klenow (2004) find that half of prices last 5.5 months excluding sales, but Nakamura and Steinsson (2008) increase this estimate to $12-13$ months excluding both sales and product substitutions. ${ }^{11}$

In our model, the degree of concentration of markets (inversely related to $n$ ) and the substitutability between goods within sectors (increasing in $\theta$ ) do affect the impact of the output gap on inflation. In particular, it is immediate to derive the following comparative statics on the slope of the Phillips curve:

Proposition 1. Under Bertrand competition and Calvo pricing the NKPC becomes flatter when the elasticity of substitution among goods increases or the number of firms decreases.

Contrary to what happens in the baseline model with monopolistic competition, the slope of the NKPC depends on the substitutability between goods. This is quite important since

\footnotetext{
${ }^{9}$ Notice that Smets and Wouters (2007) have estimated their model for the U.S. economy by replacing the Dixit-Stiglitz aggregator with the Kimball aggregator. The latter implies that the price elasticity of demand becomes increasing in the firm's price. Therefore, prices in the model become more rigid and respond by smaller amounts to shocks, for a given frequency of price changes $\lambda$. Using their macro-model, they obtain a much smaller estimate of the Calvo parameter, about $\lambda=0.67$, which implies that price contracts last 3 quarters on average, more in accordance with US microeconomic evidence (see Maćkowiak and Smets, 2008). Our setup suggests an alternative way to reconcile the micro with the macro-evidence. Needless to say, the different sources of real rigidity can be complementary.

${ }^{10}$ Under Calvo pricing the average price duration is given by $\frac{1}{1-\lambda}$. Since the period is a quarter, a value of $\lambda$ equal to 0.9 means that prices adjust on average every 10 quarters (i.e. every 30 months).

${ }^{11}$ Our model implies an even better fit to euro-area data, where as emphasized by many authors the median consumer price lasts about 3.7 quarters months (Maćkowiak and Smets, 2008).
} 
most firms compete mainly with few rivals whose products are close substitutes. And in this case high values of the demand elasticity are associated with smaller price adjustments. When $\theta$ increases, firms become less prone to change prices, because their demand is more sensitive to price differentials. As a consequence, monetary shocks have smaller effects on the inflation and therefore larger effects on the real economy. The limit behavior for (almost) homogenous goods is $\lim _{\theta \rightarrow \infty} \kappa(\theta, n)=\bar{\kappa}(n-1)^{2} /[1+n(n-1)]$, which represents the lower bound of the slope of the Phillips curve. A change in real marginal costs implies a smaller reaction of current inflation in more concentrated markets because firms tend to adjust less their prices. This is going to amplify the real impact of monetary shocks and downplay the impact of technology shocks. Another implication, is that entry of firms increases the long run slope of the Phillips curve: this is in line with the idea that globalization (larger markets) and deregulation (lower entry barriers) increase the pass through of shocks on prices (see Benigno and Faia, 2010).

\subsection{Monetary Policy}

To close the model we adopt a standard Taylor rule of the form:

$$
\hat{\imath}_{t}=\gamma_{\pi} \pi_{t}+\gamma_{x} x_{t}+\mu_{t},
$$

where $\gamma_{\pi} \in[0, \infty)$ and $\gamma_{x} \in[0, \infty)$ with at least one different from zero, and $\mu_{t}$ is a stationary monetary policy shock, following an $\operatorname{AR}(1)$ process $\mu_{t}=\rho_{\mu} \mu_{t-1}+\varepsilon_{\mu, t}$ with $\rho_{\mu} \in[0,1)$ and $\varepsilon_{\mu, t}$ white noise. To assess the determinacy of the equilibrium, we rewrite the log-linearized Euler equation (9) as a forward looking IS curve in terms of the output gap. In the absence of technology shocks this reads as:

$$
x_{t}=E_{t} x_{t+1}-\hat{\imath}_{t}+\pi_{t+1}^{e},
$$

we then substitute the Taylor rule (18) into the IS curve (19). The resulting equation and the NKPC (16) form a $2 x 2$ system, that can be rewritten in the following matrix form $\mathbf{X}_{t}=\mathbf{A} \mathbf{X}_{t+1}^{e}+\mathbf{B} \mathbf{u}_{t}$, where vector $\mathbf{X}_{t}$ includes the inflation rate $\pi_{t}$ and the output gap $x_{t}$, while $\mathbf{u}_{t}$ is the vector of all the shocks. Notice that, the model is isomorphic to the standard NK model, therefore the necessary and sufficient conditions for determinacy require:

$$
\gamma_{\pi}+\frac{1-\beta}{\kappa(\theta, n)} \gamma_{x}>1
$$

Since $(1-\beta) / \kappa(\theta, n)$ decreases in $n$ and increases in $\theta$ from Proposition 1 , we can conclude that the determinacy region enlarges in the parameter space $\left(\gamma_{\pi}, \gamma_{x}\right)$ as the number of firms decreases or the elasticity of substitution increases. The intuition is the following. Assume that, in the absence of any shock to fundamentals, there is an increase in the expected inflation. In the basic NK model a Central Bank that operates according to a Taylor rule must react by increasing the nominal interest rate enough to increase the real interest rate and to reduce current consumption, so that a negative output gap brings inflation under control. Only when the reaction of the Central Bank is strong enough, it will be able to avoid self-fulfilling inflationary expectations. In an economy with concentrated markets (low $n$ ) where few firms produce extremely substitutable goods (high $\varepsilon$ ), firms are less prone to change prices because they can lose a large portion of the customers in their market, therefore the monetary authority can use a less aggressive policy rule to avoid self-fulfilling expectations. Remarkably, the elasticity of substitution is irrelevant for determinacy in the 
standard NKPC under monopolistic competition, but it becomes relevant for concentrated markets.

With a fixed number of firms and in the absence of cost shocks, our model inherits the standard property of the NK model: as long as an appropriate labor subsidy restores the efficiency of the long-run equilibrium, by eliminating the wedge between the marginal rate of substitution (of consumption and labor) and the marginal product of labor, the short run efficient equilibrium is obtained with zero inflation rate (which is the same in terms of consumer price or producer price inflation). In the next section we will study whether this isstill the case when the number of firms is variable and endogenous. Here we study the optimal monetary policy in the presence of an exogenous cost-push shock: as we will see the number of firms and the elasticity of substitution among goods affect the prescriptions for the optimal monetary policy in the presence of a supply shock to the NKPC. Etro and Rossi (2014) have adopted the linear-quadratic approach proposed by Rotemberg and Woodford (1997) to derive the central bank loss function as a second order approximation of the households' utility function around the inefficient steady state. ${ }^{12}$ They have also shown that, with a labor subsidy restoring the steady state efficiency, the microfounded loss replicates the standard result for the welfare-based loss function. Therefore, we now adopt the following quadratic loss function:

$$
\mathcal{L}_{t}=E_{t} \sum_{k=0}^{\infty} \beta^{k}\left(\vartheta x_{t+k}^{2}+\pi_{t+k}^{2}\right)
$$

where one can microfound the relative weight on the output gap as $\vartheta=(1-\lambda)(1-\lambda \beta)(1+$ $\phi) / \lambda \theta$.

If the Central Bank cannot credibly commit in advance to a sequence of future policy actions, the optimal monetary policy is discretionary and solves the problem:

$$
\begin{aligned}
& \min _{x_{t}, \pi_{t}} \vartheta x_{t}^{2}+\pi_{t}^{2}+\mathcal{L}_{t+1} \\
& \text { s.t. : } \quad \pi_{t}=\kappa(\theta, n) x_{t}+f_{t}
\end{aligned}
$$

where $f_{t}=\beta \pi_{t+1}^{e}+\xi_{t}$ and $\mathcal{L}_{t+1}$ are taken as given. The FOC is:

$$
x_{t}=-\frac{\kappa(\theta, n)}{\vartheta} \pi_{t}
$$

and provides $x_{t}=-\kappa(\theta, n)\left(\beta \pi_{t+1}^{e}+\xi_{t}\right) /\left[\vartheta+\kappa(\theta, n)^{2}\right]$. Guessing a linear relation between $x_{t}$ and $\xi_{t}$ the method of undetermined coefficients (Clarida et al., 1999) delivers:

$$
\pi_{t}=\vartheta \Psi \xi_{t}
$$

where $\Psi=\left[\kappa(\theta, n)^{2}+\vartheta\left(1-\beta \rho_{\xi}\right)\right]^{-1}$. Substituting in (19) and using $\pi_{t+1}^{e}=\rho_{\xi} \pi_{t}$, one gets the optimal Taylor rule after replacing $\kappa(\theta, n) / \vartheta$ :

$$
\hat{\imath}_{t}=\left[1+\left(1-\rho_{\xi}\right)\left(\frac{\theta(n-1)[\theta(n-1)+1]}{\theta-1+\theta n(n-1)}-1\right)\right] \pi_{t}
$$

This is a Taylor rule of the kind (18) with $\gamma_{\pi}>1$ and $\gamma_{x}=0$, which insures determinacy. Notice that the optimal coefficient on the inflation rate is smaller compared to the case of

\footnotetext{
${ }^{12}$ They consider the case of small steady state distortions.
} 
monopolistic competition. ${ }^{13}$ Therefore, Bertrand competition with a small number of firms in each sector requires a less aggressive monetary policy compared to monopolistic competition. Moreover, straightforward comparative statics provides:

Proposition 2. Under Bertrand competition and Calvo pricing, the optimal policy requires (a constant labor subsidy and) a monetary rule reacting to inflationary shocks with a coefficient increasing in the number of firms and in the elasticity of substitution between goods.

One may notice that higher substitutability induces smaller price adjustments, which would allow for a less aggressive policy. However, when goods become more substitutable, the dispersion of consumption creates a smaller welfare loss, which asks for less output stabilization and more inflation stabilization, and therefore a more aggressive policy. This second effect is prevailing on the first one. Etro and Rossi (2014) have derived the welfare loss and a similar optimal monetary policy in the absence of the optimal labor subsidy around the distorted steady state. They examined the welfare gains from a commitment to a monetary rule finding that they decrease in more concentrated markets.

\section{Endogenous Market Structures with Sticky Prices}

Until now we have followed the traditional assumption of the NK literature of keeping exogenous the number of firms active in each market. However, the entry process is the fruit of rational investment decisions that affects the behavior of the aggregate economy and the propagation of real shocks as well as monetary shocks. It is then crucial to understand whether this strengthens the mechanism of amplification of the nominal rigidities.

In this section we adopt the same structure of the economy as before, with utility (1) and production function (5), but we augment the model with endogenous entry (details in the Appendix). Following the literature on endogenous entry (Bilbiie et al., 2008, 2012, 2014; Faia, 2012; Etro and Colciago, 2010), the number of firms active in the representative sector is now variable and follows the law of motion:

$$
n_{t}=(1-\delta)\left(n_{t-1}+n_{t-1}^{e}\right)
$$

where $\delta \in(0,1)$ is an exogenous exit probability and $n_{t}^{e}$ is the endogenous number of entrants in period $t$. Consumers can now purchase stocks of the firms, whose average value $V_{t}$ must be given by the present discounted value of the future expected dividends, or in recursive form:

$$
V_{t}=(1-\delta) E_{t}\left[\frac{\left(1+\pi_{t+1}\right)\left(V_{t+1}+d_{t+1}\right)}{1+i_{t}}\right]
$$

where the nominal interest rate must satisfy the Euler condition (6). The creation of a new firm requires a fixed investment of $\eta$ in units of output. The endogenous entry condition in each period sets $V_{t}=\eta$. The cost parameter $\eta$ will be crucial to determine the endogenous number of firms in steady state, which affects the dynamic properties of the model under strategic interactions. The resource constraint of the economy is:

$$
y_{t}=C_{t}+n_{t}^{e} V_{t}=n_{t} d_{t}+w_{t} L_{t}
$$

\footnotetext{
${ }^{13}$ For instance, assume uncorrelated shocks $\left(\rho_{\xi}=0\right)$, three firms per sector on average. Under monopolistic competition the optimal coefficient is $\gamma_{\pi}=\theta$. However, if $\theta=3$ the optimal coefficient under Bertrand competition is $\gamma_{\pi}=2.1$, and if $\theta=30$ the optimal coefficient under Bertrand competition is $\gamma_{\pi}=17.5$.
} 
In this environment, we derive a new version of NKPC that takes into account the effects of business creation into account. For simplicity, we assume (as in Bilbiie et al., 2008) that newly created firms are randomly assigned the same price of one of the existing firms, and they have the same chances to adjust or not their prices. Therefore, the average price index in the continuum of sectors is:

$$
P_{t}=\left[\lambda P_{t-1}^{1-\theta}+(1-\lambda) n_{t} p_{t}^{1-\theta}\right]^{\frac{1}{1-\theta}}
$$

whose log-linearization around a zero inflation steady state depends now on the rate of business creation:

$$
\widehat{P}_{t}=\lambda \widehat{P}_{t-1}+(1-\lambda) \widehat{p}_{t}-\frac{1-\lambda}{\theta-1} \hat{n}_{t}
$$

Loglinearizing the new equation for the optimal price and combining it with the equation above (see the Appendix for the general derivation) we obtain:

Proposition 3. Under Bertrand competition with Endogenous entry and Calvo pricing the CPI inflation rate satisfies:

$$
\pi_{t}=\beta(1-\delta) E_{t} \pi_{t+1}+\kappa \cdot \widehat{m c}_{t}+\frac{\beta(1-\delta)(1-\lambda)}{\theta-1} E_{t} \hat{n}_{t+1}-\frac{(1-\lambda)}{\lambda(\theta-1)} \hat{n}_{t}
$$

with:

$$
\kappa=\frac{(1-\lambda)[1-\lambda \beta(1-\delta)](n-1)[\theta(n-1)+1]}{\lambda[\theta-1+\theta n(n-1)]}
$$

First of all, notice that the semi-elasticitiy of inflation with respect to real marginal costs and that with respect to expected inflation are substantially the same as in the model with a fixed number of firms, reported in the previous section. The only difference is that for both the elasticities, the parameter $\beta$ is now moltiplied by the firms survival probability $(1-\delta)$. This implies that, the higher the probability of future exit $\delta$, the lower will be the overall firms' discount factor, that is $\beta(1-\delta)$. As a consequence, a higher exit probability reduces the relevance of future inflation and increases the relevance of the current real marginal cost on price adjustments. Despite these differences, Proposition 1 holds as before: under Bertrand competition with Endogenous entry and Calvo pricing the NKPC becomes flatter when the elasticity of substitution among goods increases or the number of firms decreases.

However, notice that there are two new determinants of CPI inflation: the current entry rate and the future entry rate. ${ }^{14}$ To verify the total impact of endogenous business creation on inflation, let us iterate forward the NKPC imposing zero expected inflation and zero net entry in the long run. We can easily obtain:

$$
\pi_{t}=\kappa E_{t} \sum_{k=0}^{\infty}[\beta(1-\delta)]^{k} \widehat{m c}_{t+k}-\frac{(1-\lambda)^{2}}{\lambda(\theta-1)} E_{t} \sum_{k=0}^{\infty}[\beta(1-\delta)]^{k} \hat{n}_{t+k}
$$

which shows that current inflation depends positively on the present discounted value of the future changes in the marginal cost and negatively on a discounted value of the expected net entry of firms. Current and future business creation jointly reduce the current rate of inflation because they reduce markups and the welfare-based price index, with an impact that is inversely proportional to the elasticity of substitution between goods produced by competitors (only when firms produce almost homogenous goods the number of firms does not have any impact on inflation). Therefore, endogenous entry does not affect substantially the slope of the NKPC but generates an additional source of rigidity of inflation, which is going to amplify monetary shocks even more than with a fixed number of firms.

\footnotetext{
${ }^{14}$ Remarkably, notice that the steady state number of firms affects the impact of changes in the marginal cost on inflation, but is neutral on the impact of business creation on inflation.
} 


\subsection{Impulse response functions}

To assess both the quantitative and the qualitative effects of our results, we now study the dynamics of the endogenous entry model in response to technology and monetary shocks, using the following standard parameterization: we set $\beta=0.99, \phi=1 / 4, \lambda=0.67$, and $\delta=0.025 .^{15}$ Moreover, since our framework focuses on a continuum of sectors producing goods with limited substitutability and on high inter-sectoral substitutability, we adopt a value of the elasticity of substitution that is in the high range of usual calibrations, namely $\theta=30 .^{16}$ It is important to remark that this is consistent with non-negligible markups under Bertrand competition because strategic interactions increase markups compared to monopolistic competition and the number of rivals within each sector is assumed to be low in steady state: the markup is still $7 \%$ in duopolies, $5 \%$ with three competitors, $4.3 \%$ with five firms, $3.8 \%$ with ten firms. The cost parameter $\eta$ is set to obtain three firms per sector in the steady state of the baseline model (with Bertrand competition and endogenous entry). This calibration implies that, on average, in each quarter a firm out of three does adjust its own price. ${ }^{17}$ The persistence of technology and monetary policy shocks are respectively $\rho_{a}=0.9$ and $\rho_{\mu}=0.5$. The two shocks are calibrated to have a $1 \%$ standard deviation. We consider the case in which the monetary authority implements the standard Taylor rule (18), and therefore we set $\gamma_{\pi}=1.5$ and $\gamma_{x}=0.125$. In Figures 2 and 3 we show the impulse response functions to $1 \%$ technology and monetary shocks of three models with Calvo pricing: i) the Bertrand model with endogenous entry (solid line); ii) the model with monopolistic competition and endogenous entry (croix line); iii) the standard NK model with monopolistic competition and a fixed number of firms (dotted line).
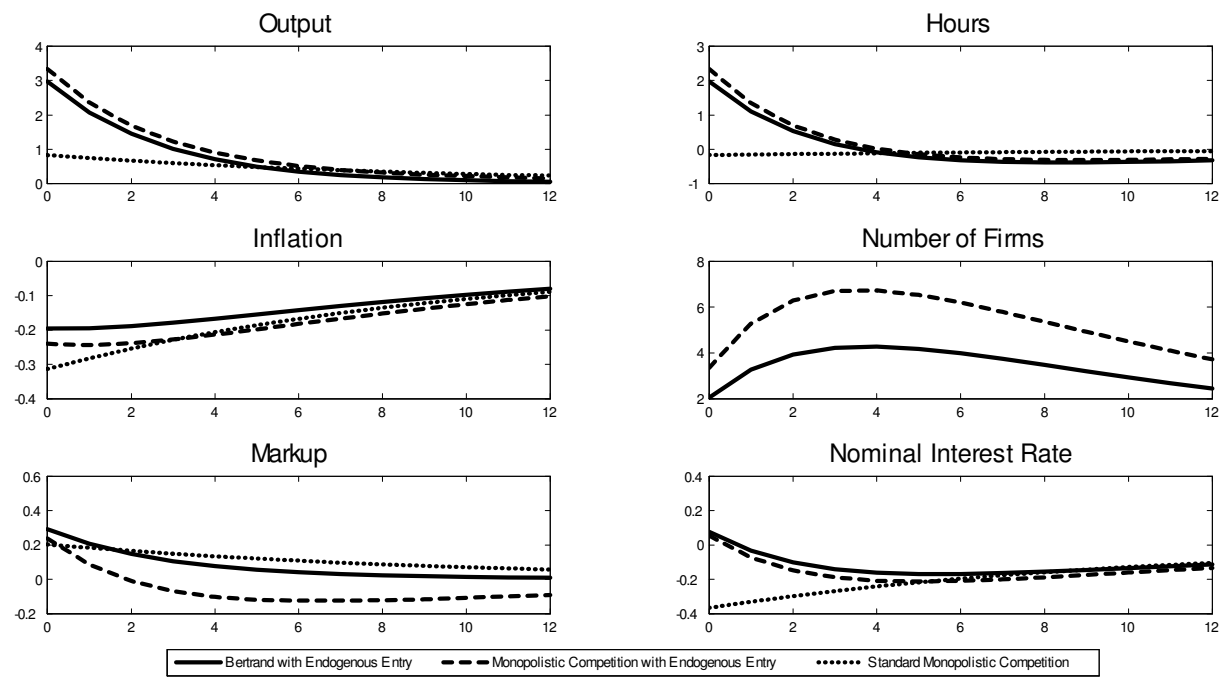

Figure 2: IRFs to $1 \%$ technology shock

\footnotetext{
${ }^{15}$ None of these parameters affect the qualitative results of the model.

${ }^{16}$ Qualitative results are not affected by the adoption of lower value of $\theta$.

${ }^{17}$ One can reinterpret the model assuming a higher number of goods produced by multiproduct firms (Minniti and Turino, 2013).
} 

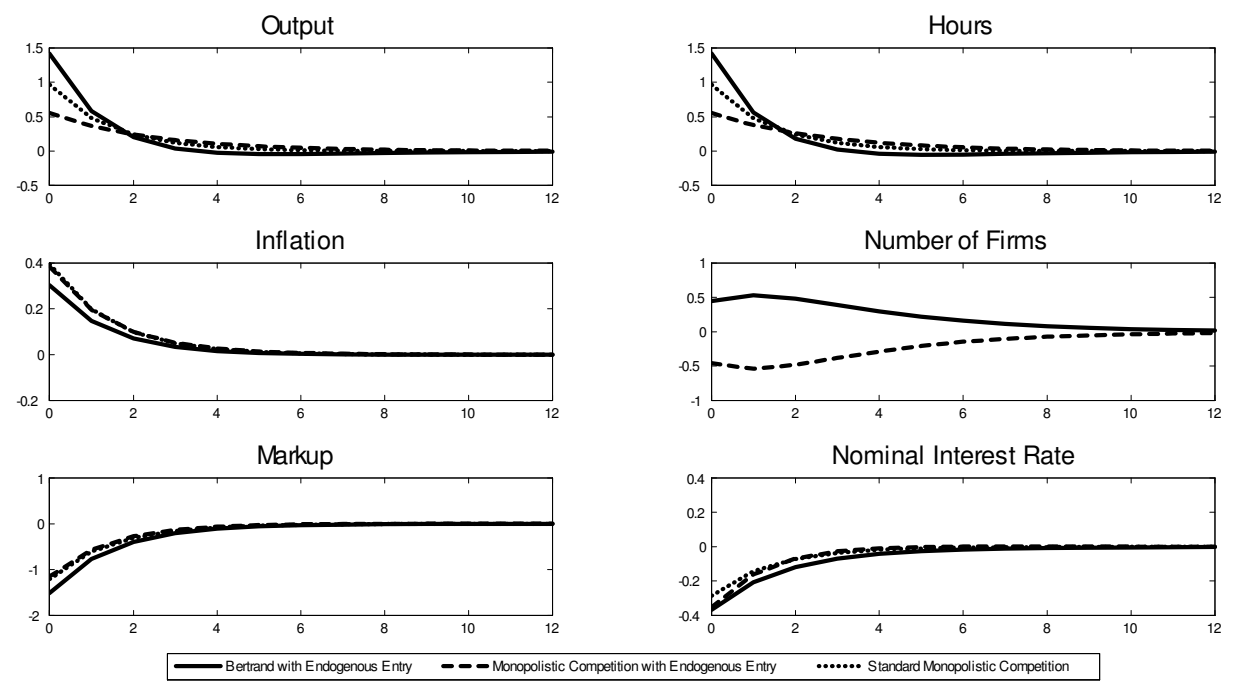

Figure 3: IRFs to $1 \%$ monetary policy shock

Let us consider first an expansionary productivity shock (Figure 2). The reduction in firms marginal costs leads to price reductions only of the firms that can adjust their prices. This effect is common to all models embedding Calvo pricing, since price staggering limits the number of firms that can adjust prices. In our model however, we have an additional source of real rigidity: strategic interactions reduce even further the endogenous size of the adjustments of the price-setters. As shown in Figure 1, the inflation rate decreases by a much smaller amount compared to the standard model with monopolistic competition and a fixed number of firms, but also compared to the model with monopolistic competition and endogenous entry (the gap with the latter is entirely due to the strategic interactions). In spite of the competition effect induced by the shock, which would reduce markups in a flexible price set-up (Etro and Colciago, 2010), the markups remain pro-cyclical in front of supply shocks due to the nominal rigidity: the stronger it is, the higher is the increase on impact of the average markup, that is the gap between average prices and lower marginal costs. Higher profitability attracts more entry generating a hump shaped pattern for the number of active firms and contributing to boost labor supply and output. The impact on output is so large as to induce a contractionary reaction of the monetary policy that partly crowds out the expansionary effect due to the negative response of inflation. As shown in the figure, this is in contrast with the expansionary reaction of monetary policy in the baseline NK model. In spite of this, the quantitative impact is largely different compared to such baseline model without both entry and strategic interactions (which generates a much smaller impact on output).

Let us now consider the case of an expansionary monetary shock (Figure 3). As usual, a reduction of the nominal interest rate leads to a reduction of the real interest rate which affects consumption and investment opportunities, boosting output and generating inflation. Nominal rigidities imply a limited reaction of inflation, as in the standard NK model, which generates a positive reaction of output. Strategic interactions due to Bertrand competition generate additional real rigidities, which induce a smaller reaction of inflation and a much higher reaction of output. The average markups are countercyclical in all the three models, in response to a monetary shocks. However notice that, a key difference between the model 
with monopolistic competition and endogenous entry and the one with Bertrand competition and endogenous entry, is that the nominal interest rate cut induces business destruction in the former and business creation in the latter, thus overcoming an important drawback characterizing the model of Bilbiie et al. (2012). Therefore, the presence of strategic interactions strongly magnifies the impact of the monetary shock on output.

\subsection{The social planner problem}

The endogenous process of business creation affects price dispersion and the gains from variety, which in turn affects welfare. Bilbiie et al. (2008) have shown that in case of monopolistic competition, Rotemberg pricing, and CES preferences, the optimal allocation of resources is simply reached with an appropriate constant labor subsidy and zero producer price inflation, which insures markup synchronization and minimizes price adjustment costs, while consumer price inflation should fluctuate to account for the entry process. We show that, when optimal fiscal tools are available and can be financed with lump sum taxes, the optimality of zero producer price inflation at all times is more demanding than usual, in case of Bertrand competition and Calvo pricing. First of all, it requires two fiscal tools, a countercyclical labor supply and a dividend tax. Second, both tools are time-dependent, and function of the number of firms currently active, which may create practical problems of implementation. The main results are summarized as follows (and proved in the Appendix):

Proposition 4. Under Bertrand competition with Endogenous entry and Calvo pricing, the optimal policy requires 1) a countercyclical labor subsidy, 2) dividend taxation, and 3) a countercyclical CPI inflation rate which induces a zero PPI inflation rate.

Since the main objective of the social planner is to obtain the efficient allocation, to understand the result it is important to keep in mind the distortions that characterize our model, i.e. the sticky price distortion, which induces price dispersion, the Bertrand competition distortion and the entry distortion. ${ }^{18}$ The distortion coming from Bertrand competition increases markups above the monopolistic competition level depending on the number of firms and induces an inefficient amount of business creation. Having this in mind, the intuition to understand our result is straightforward. On one side, the optimal CPI inflation rate

$$
\pi_{t}^{*}=\left(\frac{n_{t}}{n_{t-1}}\right)^{1 /(1-\theta)}-1
$$

decreases when net entry is positive, and induces stable producer prices. This eliminates price dispersion and thus the variability of output between firms. On the other side, the labor subsidy and the dividend tax are chosen to eliminate the markup and to reproduce the efficient equilibrium in terms of labor supply and business creation. The optimal labor subsidy is:

$$
\tau_{t}^{*}=\frac{n_{t}}{(\theta-1)\left(n_{t}-1\right)}
$$

which is countercyclical since it decreases in the number of firms active in each period. The

\footnotetext{
${ }^{18}$ Notice that Bilbiie et al. (2008), consider a model with monopolistic competition and Rotemberg (1982) pricing and thus price dispersion is absent in their model. However, the Rotemberg framework is characterized by the precence of convex price adjustment costs. Under monopolistic competition price dispersion and price adjustment costs affect differently the slope of the NKPC and both the steady state and the model dynamics up to a second order approximation. Nevertheless, the two sticky price distortions move in the same direction of reducing the level of output as inflation increases.
} 
optimal dividend tax is:

$$
\tau_{t}^{* D}=\frac{\theta-1-n_{t}}{n_{t}(\theta-1)}
$$

which is positive with few firms and negative (as under monopolistic competition) only if the number of firms is large enough. In case of a small number of firms and high elasticity of substitution, this delivers a positive and countercyclical dividend taxation. ${ }^{19}$ Alternative but equivalent optimal taxation systems are discussed in Etro (2009, Ch. 3).

\subsection{The Ramsey optimal steady state}

We now derive the Ramsey optimal steady state of our model, in the absence of fiscal tools. ${ }^{20}$ Looking at the Ramsey optimal steady state inflation rate amounts to computing the modified golden rule steady state inflation, i.e. the steady state inflation rate obtained imposing steady state conditions ex post on the first order conditions of the Ramsey plan. ${ }^{21}$ The optimal Ramsey plan is determined by the Central Bank to maximize the discounted sum of utilities of all agents given the constraints of the competitive economy, assuming that an ex ante commitment is feasible. Notably, the Ramsey approach allows to study the optimal policy around a distorted steady state, as it is in our model. ${ }^{22}$

One may expect that in the absence of fiscal instruments, some producer price inflation could be used to reduce the average markups and the rate of business creation, that are both above the efficient steady state level under Bertrand competition. Faia (2012) has shown that the optimal steady state inflation is still zero under Rotemberg pricing. This result is justified by the fact that the Rotemberg convex costs of price adjustment are the dominant distortions cancelled only under zero steady state infation. Similarly, we show that zero inflation remains the optimal steady state also in the precence of Calvo pricing. In other words, the costs in terms of price dispersions associated with Calvo pricing under a positive inflation are still too high to justify a systematic use of the inflationary tool to address the two mentioned inefficiencies. Thus, as in the standard NK model (King and Wolman, 1999, Schmitt-Grohe and Uribe, 2011) and as in the Faia (2012), also in our case with staggered prices à la Calvo the Ramsey problem, obtained assuming a timeless perspective, delivers zero inflation in steady state (see the Appendix). Thus, we can state:

Proposition 5. Under Bertrand competition with Endogenous entry and Calvo pricing, the optimal monetary policy without fiscal tools requires zero CPI inflation rate in steady state.

In spite of inefficient entry under Bertrand competition, the cost of the distortions associated with positive inflation cannot be compensated by the impact of inflation on entry, which leaves zero inflation optimal in the long run. Augmenting the model with more general

\footnotetext{
${ }^{19}$ Notice that with monopolistic competition we need only one constant tax tool, since

$$
\lim _{n_{t} \rightarrow \infty} \tau_{t}^{*}=\lim _{n_{t} \rightarrow \infty}\left(-\tau_{t}^{* D}\right)=\frac{1}{\theta-1}
$$

${ }^{20}$ We follow the methodology of Schmitt-Grohe and Uribe (2011). All the derivations are reported in the Appendix.

${ }^{21}$ The Ramsey steady-state equilibrium was calculated numerically by using an OLS approach, as described by Schmitt-Grohé and Uribe (2012).

${ }^{22}$ See also King and Wolman (1999), Yun (2005), and in particular Khan et al. (2003), Schmitt-Grohé and Uribe (2007), Faia (2009) and Faia and Rossi (2013) for a discussion on welfare analysis with a distorted steady state.
} 
homothetic preferences as in Bilbiie et al. (2014) would generate non-zero long run inflation also under Bertrand competition.

\subsection{Calvo vs Rotemberg pricing}

The first NK models with endogenous entry by Bilbiie et al. $(2008,2014)$ and Faia $(2012)$ neglected price staggering but assumed sticky prices with adjustment costs à la Rotemberg (1982), and it is therefore useful to compare those models with ours. A recent work by Lewis and Poilly (2012) has augmented such models with other extensions for estimation purposes. In these models, the marginal profitability of a price adjustment increases with competition, therefore, an increase in substitutability between goods has the opposite effect compared to our model: it increases the extent to which (all) firms adjust their prices. However, like in our setup, a reduction in the number of firms increases the markups and reduces the extent to which firms adjust their prices. Adopting a nominal price adjustment cost as $(\chi / 2)\left[p_{t}(i) / p_{t-1}(i)-1\right]^{2} p_{t}(i) C_{t}(i)$ for each firm $i$ facing demand $C_{t}(i)$ at time $t$, with $\chi>0$, the price setting decisions lead to the following NKPC in terms of the consumer price inflation:

$$
\pi_{t}=\beta(1-\delta) E_{t} \pi_{t+1}+\frac{(\theta-1)(n-1)}{\chi n} \widehat{m c}_{t}+\frac{\beta(1-\delta) E_{t} \widehat{n}_{t+1}+\widehat{n}_{t-1}}{\theta-1}-\varrho(n) \hat{n}_{t}
$$

where $\varrho(n)$ is a parameter derived in the Appendix. ${ }^{23}$ The introduction of strategic interactions reduces the slope of the NKPC under both Calvo and Rotemberg pricing (though for different reasons), but an increase in substitutability between goods $\theta$ makes the NKPC steeper under Rotemberg pricing and less steep under Calvo pricing. Moreover, the impact of past, current and future entry on inflation is qualitatively different in the two models. ${ }^{24}$

The empirical analysis of Lewis and Poilly (2012) has found a small competition effect in their model with strategic interactions. This is not surprising since (besides various differences between setups) they focus on a relatively high number of firms and low inter-sectoral substitutability. ${ }^{25}$ It would be interesting to estimate the present model focusing on concentrated markets with high inter-sectoral substitutability.

\subsection{Product substitution}

The model with staggered pricing can be extended in many directions to enrich the propagation mechanism and augment persistence of inflation. Besides traditional directions, such as introducing capital accumulation, consumption habits or wage stickiness, we will point out one that is peculiar to the current setup. ${ }^{26}$ As Nakamura and Steinsson (2008) have shown, a relevant portion of price changes is actually associated with the introduction of new products. We can account for this by assuming that the new entrants adopt right away the optimal price for their new products: this implies that an expansionary monetary shock gradually attracts new price-setting firms and induces a growing inflationary pressure. In each period,

\footnotetext{
${ }^{23}$ This expression goes back to the result in Bilbiie et al. (2008) under monopolistic competition (for $n \rightarrow \infty)$ and is a particular case of the result in Lewis and Poilly (2012).

${ }^{24}$ Remarkably, this is a new case in which Calvo and Rotemberg pricing do not deliver NKPCs that are observationally equivalent as in the baseline model (see Ascari and Rossi, 2012, for the case of trend inflation).

${ }^{25}$ In particular, their calibration implicitly assumes $\eta=1$, which leads to a steady state number of firms high enough to limit the competition effect. Moreover, in the simulations they confine the range of values for $\theta$ under $\theta=4$, which again limits the strength of the competition effect.

${ }^{26}$ Further details on the derivation of the NKPC and simulations are available from the authors.
} 
a fraction $\lambda$ of the $(1-\delta) n_{t-1}$ previously active firms cannot adjust the nominal price and has to maintain the pre-determined price, and the remaining fraction $1-\lambda$ plus all the new active entrants $n_{t}-(1-\delta) n_{t-1}$ can choose optimally the new price $p_{t}$. The price index must satisfy

$$
P_{t}^{1-\theta}=\lambda(1-\delta) P_{t-1}^{1-\theta}+\left[n_{t}-\lambda(1-\delta) n_{t-1}\right] p_{t}^{1-\theta}
$$

which leads to the following modified NKPC:

$$
\pi_{t}=\beta E_{t} \pi_{t+1}+\kappa \cdot \widehat{m c} t+\frac{\beta E_{t}\left\{\hat{n}_{t+1}\right\}+\hat{n}_{t-1}}{\theta-1}-\frac{1+\beta[\lambda(1-\delta)]^{2}}{\lambda(1-\delta)(\theta-1)} \hat{n}_{t}
$$

where the slope remains unchanged, but both past and future business creation are pushing up current inflation. In such a model, the impact of expansionary shocks generates additional business creation, due to the advantage that new firms have (relative to the incumbents) in choosing optimal prices. ${ }^{27}$

\section{Conclusion}

We have reconsidered the New-Keynesian framework under time-dependent staggered pricing à la Calvo in markets characterized by a small number of competitors engaged in Bertrand competition. Such a description of the relevant form of competition can be quite realistic from an industrial organization point of view. Most local markets for traditional goods and services do involve a small number of competitors and represent a big portion of our economies. However, also many global markets tend to be highly concentrated because of a process of escalation of R\&D costs. In these conditions, strategic interactions cannot be ignored and create important real rigidities that affect the propagation of shocks. Price adjusters do change their prices less when there are more firms that do not adjust: this strengthens the impact of nominal rigidities, which is at the heart of New-Keynesian economics. Further, Bertrand competition affects the fiscal policy prescriptions to restore the social planner allocation and alter the optimal interest rate rule, by requiring a more accommodative policy in response to supply shocks.

\section{References}

Altig, David, Lawrence Christiano, Martin Eichenbaum and Jesper Linde, 2011, Firm-Specific Capital, Nominal Rigidities and the Business Cycle, Review of Economic Dynamics, 14, $2,225-47$

Ascari, Guido and Lorenza Rossi, 2012, Trend Inflation and Firms Price-Setting: Rotemberg Versus Calvo, Economic Journal, 122, 563, 1115-41

Auray, Stéphane, Aurélien Eyquem and Jean-Christophe Poutineau, 2012, The Effect of a Common Currency on the Volatility of the Extensive Margin of Trade, Journal of International Money and Finance, 31, 1156-79

Ball, Laurence and David Romer, 1990, Real Rigidities and the Non-neutrality of Money, Review of Economic Studies, 57, 2, 183-203

\footnotetext{
${ }^{27}$ Notice that the mechanics of such a model in general equilibrium is complicated by the different values of new firms (price-setters by assumption) and incumbent firms. However, the advantage in price-setting for the new born firms does not appear to be an entirely realistic source of business creation.
} 
Basu, Susanto, 1995, Intermediate Goods and Business Cycles: Implications for Productivity and Welfare, The American Economic Review, 85, 3, 512-31

Benigno, Pierpaolo and Ester Faia, 2010, Globalization, Pass-Through and Inflation Dynamic, NBER WP 15842

Benigno, Pierpaolo and Michael Woodford, 2005, Inflation Stabilization And Welfare: the Case of a Distorted Steady State, Journal of the European Economic Association, 3, 6, $1185-236$

Bergin, Paul and Robert Feenstra, 2000, Staggered Price Setting, Translog Preferences, and Endogenous Persistence, Journal of Monetary Economics, 45, 3, 657-80

Bilbiie, Florin, Fabio Ghironi and Marc Melitz, 2008, Monetary Policy and Business Cycles with Endogenous Entry and Product Variety, in NBER Macroeconomic Annual 200\%, D. Acemoglu, K. Rogoff and M. Woodford Eds., 299-353

Bilbiie, Florin, Fabio Ghironi and Marc Melitz, 2012, Endogenous Entry, Product Variety, and Business Cycles, Journal of Political Economy, 120, 2, 304-45

Bilbiie, Florin, Ippei Fujiwara and Fabio Ghironi, 2014, Optimal Monetary Policy with Endogenous Entry and Product Variety, Journal of Monetary Economics, forthcoming

Bils, Mark and Peter Klenow, 2004, Some Evidence on the Importance of Sticky Prices, Journal of Political Economy, 112, 5, 947-85

Calvo, Guillermo, 1983, Staggered Prices in a Utility-Maximizing Framework, Journal of Monetary Economics, 12, 3, 383-98

Campbell, Jeffrey and Hugo Hopenhayn, 2005, Market Size Matters, Journal of Industrial Economics, 53, 1, 1-25

Cavallari, Lilia, 2013, A Note on Firm Entry, Markups and the Business Cycle, Economic Modelling, 35, 528-35

Cecioni, Martina, 2010, Firm Entry, Competitive Pressures and the U.S. Inflation Dynamics, Bank of Italy WP 773

Clarida, Richard, Mark Gertler and Jordi Gali, 1999, The Science of Monetary Policy: A New Keynesian Perspective, Journal of Economic Literature, 37, 4, 1661-707

Colciago, Andrea and Federico Etro, 2010, Real Business Cycles with Cournot Competition and Endogenous Entry, Journal of Macroeconomics, Vol. 32, 4, 1101-17

Colciago, Andrea and Lorenza Rossi, 2011, Endogenous Market Structures and the Labor Market, WP 139, University of Pavia

Dixit, Avinash and Joseph Stiglitz, 1977, Monopolistic Competition and Optimum Product Diversity, The American Economic Review, 67, 297-308

Dotsey, Michael and Robert King, 2005, Implications of State-dependent Pricing for Dynamic Macroeconomic Models, Journal of Monetary Economics, 52, 1, 213-42

Etro, Federico, 2009, Endogenous Market Structures and the Macroeconomy, New York and Berlin, Springer

Etro, Federico and Andrea Colciago, 2010, Endogenous Market Structures and the Business Cycle, The Economic Journal, 120, 1201-34

Etro, Federico and Lorenza Rossi, 2014, Staggered Price Setting, Bertrand Competition and Optimal Monetary Policy, DEM WP Series 071, University of Pavia, Department of Economics and Management

Faia, Ester, 2009. Ramsey Monetary Policy with Labor Market Frictions, Journal of Monetary Economics, 56, 570-581

Faia, Ester and Lorenza Rossi, 2013. Unions Power, Collective Bargaining and Optimal Monetary, Economic Enquiry, 51, 1, 408-427

Faia, Ester, 2012, Oligopolistic Competition and Optimal Monetary Policy, Journal of Economic Dynamics \& Control, 36, 11, 1760-74 
Feenstra, Robert and David Weinstein, 2010, Globalization, Markups, and the U.S. Price Level, NBER WP 15749

Galì, Jordi, 2008, Monetary Policy, Inflation and the Business Cycle: An Introduction to the New Keynesian Framework, Princeton University Press

Galì, Jordi and Mark Gertler, 1999, Inflation Dynamics: A Structural Econometric Analysis, Journal of Monetary Economics, 44, 2, 195-222

Kimball, Miles, 1995, The Quantitative Analytics of the Basic Neomonetarist Model, Journal of Money, Credit and Banking, 27, 4, 1241-77

Khan, Aubhik, Robert King, Alexander Wolman, 2003, Optimal Monetary Policy, Review of Economic Studies, 70, 825-60

King, Robert and Alexander Wolman, 1996, Inflation Targeting in a St. Louis Model of the 21st century, Federal Reserve Bank of St. Louis Review 78, 83-107

King, Robert and Alexander Wolman, 1999, What Should the Monetary Authority Do When Prices Are Sticky?, NBER Chapters, in: Monetary Policy Rules, 349-404

Levin, Andrew, J. David Lopez-Salido and Tack Yun, 2007, Strategic Complementarities and Optimal Monetary Policy, CEPR Discussion Papers 6423

Lewis, Vivien and Celine Poilly, 2012, Firm Entry, Markups and the Monetary Transmission Mechanism, Journal of Monetary Economics, 59, 7, 670-85

Lewis, Vivien and Roland Winkler, 2013, Entry and Markup Dynamics in an Estimated Business Cycle Model, Center for Economic Studies - DP 13.20, Katholieke Universiteit Leuven

Maćkowiak, Bartosz and Frank Smets, 2008, On Implications of Micro Price Data for Macro Models, WP Series 0960, European Central Bank

Minniti, Antonio and Francesco Turino, 2013, Multi-product Firms and Business Cycle Dynamics, European Economic Review, 57, 75-97

Nakamura, Emi and Jón Steinsson, 2008, Five Facts about Prices: A Reevaluation of Menu Cost Models, Quarterly Journal of Economics, 123, 4, 1415-64

Nakamura, Emi and Jón Steinsson, 2013, Price Rigidity: Microeconomic Evidence and Macroeconomic Implications, NBER WP 18705

Rotemberg, Julio, 1982, Monopolistic Price Adjustment and Aggregate Output, Review of Economic Studies, 49, 4, 517-31

Rotemberg, Julio and Michael Woodford, 1997, An Optimization-based Econometric Framework for the Evaluation of Monetary Policy, in NBER Macroeconomic Annual, 2, 297-346

Rotemberg, Julio and Michael Woodford, 2000, The Cyclical Behavior of Prices and Costs, Ch. 16 in Handbook of Macroeconomics, J. B. Taylor and M. Woodford Eds., Elsevier, 1, 1051-135

Sbordone, Argia, 2007, Globalization and Inflation Dynamics: The Impact of Increased Competition, in International Dimensions of Monetary Policy, NBER, 547-579

Schmitt-Grohé, Sthephanie and Martin Uribe, 2007. Optimal, Simple, and Implementable Monetary and Fiscal Rules, Journal of Monetary Economics, 54, 1702-1725

Schmitt-Grohé, Stephanie and Martin Uribe, 2011, The Optimal Rate of Inflation, in Handbook of Monetary Economics, Eds. B. Friedman and M. Woodford, Vol. 3B, Elsevier, San Diego CA, 653-722

Schmitt-Grohé, Stephanie and Martin Uribe, 2012. An OLS Approach to Computing Ramsey Equilibria in Medium-Scale Macroeconomic Models, Economics Letters, 115, 128-129

Smets, Frank, and Rafael Wouters. 2003. An Estimated Dynamic Stochastic General Equilibrium Model of the Euro Area. Journal of the European Economic Association, 1, 5, $1123-75$ 
Smets, Frank and Rafael Wouters, 2007, Shocks and Frictions in US Business Cycles: A Bayesian DSGE Approach, The American Economic Review, 97, 3, 586-606

Sutton, John, 1991, Sunk Costs and Market Structure: Price Competition, Advertising, and the Evolution of Concentration, MIT Press, London

Taylor, John, 1979, Staggered Wage Setting in a Macro Model, The American Economic Review, 69 2, 108-13

Yun, Tack, 1996, Nominal Price Rigidity, Money Supply Endogeneity, and Business Cycles, Journal of Monetary Economics, 37, 2-3, 345-70

Yun, Tack, 2005, Optimal Monetary Policy with Relative Price Distortions, The American Economic Review, 95, 1, 89-109

Woodford, Michael, 2003, Interest and Prices, Princeton University Press

\section{Appendix A: The Modified NKPC}

Let us consider the representative sector with the usual CES consumption index:

$$
C_{t}=\left[\sum_{j=1}^{n_{t}} C_{t}(j)^{\frac{\theta-1}{\theta}}\right]^{\frac{\theta}{\theta-1}}
$$

which implies that demand at time $t$ of good $i$ is $C_{t}(i)=\left[p_{t}(i) / P_{t}\right]^{-\theta} C_{t}$, where $p_{t}(i)$ is the price of the firm and the average price index is:

$$
P_{t}=\left[\sum_{j=1}^{n_{t}} p_{t}(j)^{1-\theta}\right]^{\frac{1}{1-\theta}}
$$

\section{Calvo pricing}

In each period, a fraction $\lambda$ of the firms cannot adjust the nominal price and maintains the pre-determined price, and a fraction $1-\lambda$ can reoptimize the nominal price to the optimal level $p_{t}$, which maximizes the discounted value of future profits. Therefore, the average price index must be:

$$
P_{t}=\left[\lambda P_{t-1}^{1-\theta}+(1-\lambda) n_{t} p_{t}^{1-\theta}\right]^{\frac{1}{1-\theta}}
$$

whose log-linearization around a zero inflation steady state is:

$$
\widehat{P}_{t}=\lambda \widehat{P}_{t-1}+(1-\lambda) \widehat{p}_{t}-\frac{1-\lambda}{\theta-1} \hat{n}_{t}
$$

which depends on the change of the number of firms. In every period $t$, each optimizing firm $i$ chooses the same new price $p_{t}$ to maximize the expected profits until the next adjustment, taking into account the exogenous probability of exit at each period $\delta$ and the probability that there will be a new adjustment $\lambda$ :

$$
\max _{p_{t}} E_{t} \sum_{k=0}^{\infty}(1-\delta)^{k} \lambda^{k}\left\{Q_{t+k}\left[p_{t}-M C_{t+k}\right]\left(\frac{p_{t}}{P_{t+k}}\right)^{-\theta} C_{t+k}\right\}
$$

where $M C_{t}$ is nominal marginal cost, $Q_{t+k}=\beta^{k} P_{t} C_{t} / P_{t+k} C_{t+k}$ is the stochastic discount factor, and we used the fact that demand at time $t+k$ is $C_{t+k}(i)=\left[p_{t}(i) / P_{t+k}\right]^{-\theta} C_{t+k}$. The problem can be simplified as:

$$
\max _{p_{t}} E_{t} \sum_{k=0}^{\infty} \gamma^{k} \frac{\left[p_{t}-M C_{t+k}\right] p_{t}{ }^{-\theta} I_{t}}{\sum_{j=1}^{n_{t+k}} p_{t+k}(j)^{1-\theta}}
$$


where $\gamma \equiv \lambda \beta(1-\delta)$ and expenditure $I_{t}=P_{t} C_{t}$ is taken as given. Notice that at each time $t+k$ the denominator $\sum_{j=1}^{n_{t+k}} p_{t+k}(j)^{1-\theta}$ includes a fraction $\lambda$ of the $n_{t}$ firms that cannot adjust the nominal price, maintaining the pre-determined price level and a fraction $1-\lambda$ that can reoptimize. The FOC of this problem provides, after imposing symmetry:

$$
p_{t} E_{t} \sum_{k=0}^{\infty} \frac{\gamma^{k}}{P_{t+k}^{1-\theta}}-\theta E_{t} \sum_{k=0}^{\infty} \frac{\gamma^{k}\left(p_{t}-M C_{t+k}\right)}{P_{t+k}^{1-\theta}}=(1-\theta) p_{t}^{1-\theta} E_{t} \sum_{k=0}^{\infty} \frac{\gamma^{k}\left(p_{t}-M C_{t+k}\right)}{P_{t+k}^{2(1-\theta)}}
$$

where we used $P_{t+k}^{1-\theta}=\sum_{j=1}^{n_{t+k}} p_{t+k}(j)^{1-\theta}$. The FOC can be rearranged as:

$$
\left(\frac{p_{t}}{P_{t}}\right) F_{t}=K_{t}+\left(\frac{p_{t}}{P_{t}}\right)^{2-\theta} G_{t}-\left(\frac{p_{t}}{P_{t}}\right)^{1-\theta} H_{t}
$$

where

$$
F_{t} \equiv E_{t} \sum_{k=0}^{\infty}(\lambda \beta)^{k}\left(P_{t+k} / P_{t}\right)^{\theta-1}
$$

and

$$
K_{t} \equiv \frac{\theta}{\theta-1} E_{t} \sum_{k=0}^{\infty}(\lambda \beta)^{k} m c_{t+k}\left(P_{t+k} / P_{t}\right)^{\theta}
$$

which correspond to the terms emerging under monopolistic competition (see Benigno and Woodford, 2005), plus:

$$
G_{t} \equiv E_{t} \sum_{k=0}^{\infty}(\lambda \beta)^{k}\left(P_{t+k} / P_{t}\right)^{2(\theta-1)}
$$

and

$$
H_{t} \equiv E_{t} \sum_{k=0}^{\infty}(\lambda \beta)^{k} m c_{t+k}\left(P_{t+k} / P_{t}\right)^{2 \theta-1}
$$

A closed form solution for $p_{t} / P_{t}$ is not available as it was for monopolistic competition. However, the steady state implies:

$$
\left[1-\theta\left(1-\frac{M C}{p}\right)-(1-\theta)(p / P)^{1-\theta}\left(1-\frac{M C}{p}\right)\right]=0
$$

and $(p / P)^{1-\theta}=1 / n$, therefore we can express the long run Lerner index as:

$$
\frac{p-M C}{p}=\frac{n}{\theta n+1-\theta}
$$

We split the FOC in four parts. The log-linearization of $p_{t} \sum_{k=0}^{\infty} \gamma^{k}\left(P_{t+k}\right)^{\theta-1}$ is:

$$
\begin{aligned}
& p\left(1+\hat{p}_{t}\right) E_{t} \sum_{k=0}^{\infty} \gamma^{k} P^{\theta-1}\left(1+(\theta-1) \hat{P}_{t+k}\right) \\
= & p P^{\theta-1} \sum_{k=0}^{\infty} \gamma^{k}+p P^{\theta-1}(\theta-1) E_{t} \sum_{k=0}^{\infty} \gamma^{k} \hat{P}_{t+k}+p P^{\theta-1} \hat{p}_{t} \sum_{k=0}^{\infty} \gamma^{k}
\end{aligned}
$$

The log-linearization of $\theta E_{t} \sum_{k=0}^{\infty} \gamma^{k}\left(p_{t}-M C_{t+k}\right)\left(P_{t+k}\right)^{\theta-1}$ is:

$$
\begin{aligned}
& \theta E_{t} \sum_{k=0}^{\infty} \gamma^{k}\left[p\left(1+\hat{p}_{t}\right)-M C\left(1+\widehat{M C}_{t+k}\right)\right] P^{\theta-1}\left(1+(\theta-1) \hat{P}_{t+k}\right) \\
= & \theta \sum_{k=0}^{\infty} \gamma^{k} P^{\theta-1}(p-M C)+\theta(\theta-1) P^{\theta-1}(p-M C) E_{t} \sum_{k=0}^{\infty} \gamma^{k} \hat{P}_{t+k} \\
& +\theta P^{\theta-1} p \hat{p}_{t} \sum_{k=0}^{\infty} \gamma^{k}-\theta p P^{\theta-1} \frac{M C}{p} E_{t} \sum_{k=0}^{\infty} \gamma^{k} \widehat{M C} \widehat{M}_{t+k}
\end{aligned}
$$


The log-linearization of $(1-\theta) p_{t}^{2-\theta} E_{t} \sum_{k=0}^{\infty} \gamma^{k}\left(P_{t+k}\right)^{2(\theta-1)}$ is:

$$
\begin{aligned}
& (1-\theta)\left[p^{2-\theta}\left(1+(2-\theta) \hat{p}_{t}\right)\right] E_{t} \sum_{k=0}^{\infty} \gamma^{k} P^{2(\theta-1)}\left[1+2(\theta-1) \hat{P}_{t+k}\right] \\
= & (1-\theta) p^{2-\theta} P^{2(\theta-1)}-(1-\theta) p^{2-\theta} P^{2(\theta-1)}(\theta-2) \hat{p}_{t} \sum_{k=0}^{\infty} \gamma^{k}+ \\
& -2(1-\theta)^{2} p^{2-\theta} P^{2(\theta-1)} E_{t} \sum_{k=0}^{\infty} \gamma^{k} \hat{P}_{t+k}
\end{aligned}
$$

Finally, the log-linearization of $(1-\theta) p_{t}^{1-\theta} E_{t} \sum_{k=0}^{\infty} \gamma^{k} M C_{t+k}\left(P_{t+k}\right)^{2(\theta-1)}$ is:

$$
\begin{aligned}
& (1-\theta) p^{1-\theta}\left[1+(1-\theta) \hat{p}_{t}\right] E_{t} \sum_{k=0}^{\infty} \gamma^{k} M C\left(1+\widehat{M C}_{t+k}\right) P^{2(\theta-1)}\left(1+2(\theta-1) \widehat{P}_{t+k}\right) \\
= & (1-\theta) M C p^{1-\theta} P^{2(\theta-1)} \sum_{k=0}^{\infty} \gamma^{k}+(1-\theta)^{2} M C p^{1-\theta} P^{2(\theta-1)} \widehat{p}_{t} \sum_{k=0}^{\infty} \gamma^{k}+ \\
& +(1-\theta) M C p^{1-\theta} P^{2(\theta-1)} E_{t} \sum_{k=0}^{\infty} \gamma^{k} \widehat{M C}_{t+k}-2(1-\theta)^{2} M C p^{1-\theta} P^{2(\theta-1)} E_{t} \sum_{k=0}^{\infty} \gamma^{k} \widehat{P}\left(t \epsilon_{k}\right)
\end{aligned}
$$

Simplifying for the constant terms through the steady state relation we get:

$$
\begin{aligned}
0= & p P^{\theta-1}(\theta-1) E_{t} \sum_{k=0}^{\infty} \gamma^{k} \hat{P}_{t+k}+p P^{\theta-1} \hat{p}_{t} \sum_{k=0}^{\infty} \gamma^{k}+ \\
- & \theta(\theta-1) p P^{\theta-1}\left(1-\frac{M C}{p}\right) E_{t} \sum_{k=0}^{\infty} \gamma^{k} \hat{P}_{t+k}+ \\
- & \theta P^{\theta-1} p \hat{p}_{t} \sum_{k=0}^{\infty} \gamma^{k}+\theta p P^{\theta-1} \frac{M C}{p} E_{t} \sum_{k=0}^{\infty} \gamma^{k} \widehat{M C}{ }_{t+k}+ \\
& -(1-\theta) p^{2-\theta} P^{2(\theta-1)}(2-\theta) \hat{p}_{t} \sum_{k=0}^{\infty} \gamma^{k}+ \\
& +2(1-\theta)^{2} p^{2-\theta} P^{2(\theta-1)} E_{t} \sum_{k=0}^{\infty} \gamma^{k} \hat{P}_{t+k}+ \\
& +(1-\theta)^{2} p^{1-\theta} \frac{M C}{p} p P^{2(\theta-1)} \widehat{p}_{t} \sum_{k=0}^{\infty} \gamma^{k}+ \\
+ & (1-\theta) p^{1-\theta} \frac{M C}{p} p P^{2(\theta-1)} E_{t} \sum_{k=0}^{\infty} \gamma^{k} \widehat{M C} \widehat{C}_{t+k}+ \\
- & 2(1-\theta)^{2} p^{1-\theta} \frac{M C}{p} p P^{2(\theta-1)} E_{t} \sum_{k=0}^{\infty} \gamma^{k} \widehat{P}_{t+k}
\end{aligned}
$$

Notice that $p P^{\theta-1}$ multiplies everything. Cancelling it and collecting terms in $\widehat{p}_{t}, \widehat{P}_{t+k}$, and $\widehat{M C}_{t+k}$ we have:

$$
a_{0} \hat{p}_{t} \sum_{k=0}^{\infty} \gamma^{k}+a_{1} E_{t} \sum_{k=0}^{\infty} \gamma^{k} \widehat{P}_{t+k}+a_{2} E_{t} \sum_{k=0}^{\infty} \gamma^{k} \widehat{M C}_{t+k}=0
$$


where, using the steady state conditions $(p / P)^{1-\theta}=1 / n$ and (42) we obtain:

$$
\begin{aligned}
& a_{0}=-\frac{\theta-1}{n}\left[n+\theta-2-\frac{(\theta-1)^{2}(n-1)}{\theta n+1-\theta}\right] \\
& a_{1}=\frac{(\theta-1)^{2}}{\theta n+1-\theta} \\
& a_{2}=\frac{(\theta-1)(n-1)}{n}
\end{aligned}
$$

To rewrite the expression above in terms of the real marginal cost we add and subtract $a_{2} \sum_{k=0}^{\infty} \gamma^{k} \widehat{P}_{t+k}$, so that we define $\widehat{m c}_{t+k}=\widehat{M C}_{t+k}-\widehat{P}_{t+k}$ and (47) becomes:

$$
a_{0} \hat{p}_{t} \sum_{k=0}^{\infty} \gamma^{k}+\left(a_{1}+a_{2}\right) E_{t} \sum_{k=0}^{\infty} \gamma^{k} \widehat{P}_{t+k}+a_{2} E_{t} \sum_{k=0}^{\infty} \gamma^{k} \widehat{m c}_{t+k}=0
$$

One can verify that $a_{1}+a_{2}=-a_{0}$. Therefore we can rewrite:

$$
a_{0} \hat{p}_{t} \sum_{k=0}^{\infty} \gamma^{k}-a_{0} E_{t} \sum_{k=0}^{\infty} \gamma^{k} \widehat{P}_{t+k}+a_{2} E_{t} \sum_{k=0}^{\infty} \gamma^{k} \widehat{m c}_{t+k}=0
$$

and solve for $\hat{p}_{t}$ in recursive form:

$$
\hat{p}_{t}=[1-\lambda \beta(1-\delta)] \widehat{P}_{t}-[1-\lambda \beta(1-\delta)] \frac{a_{2}}{a_{0}} \widehat{m c}_{t}+\lambda \beta(1-\delta) E_{t} \hat{p}_{t+1}
$$

In order to substitute for $\hat{p}_{t}$ and $\hat{p}_{t+1}$, consider the log-linearization of the price index (37). Solving it for $\hat{p}_{t}$ we have:

$$
\hat{p}_{t}=\frac{\widehat{P}_{t}-\lambda \widehat{P}_{t-1}}{1-\lambda}+\frac{\hat{n}_{t}}{\theta-1}
$$

so that $E_{t} \hat{p}_{t+1}=\left(E_{t} \widehat{P}_{t+1}-\lambda \widehat{P}_{t}\right) /(1-\lambda)+E_{t} \hat{n}_{t+1} /(\theta-1)$. Substituting both into (50) we have:

$$
\begin{aligned}
& \frac{\widehat{P}_{t}-\lambda \widehat{P}_{t-1}}{1-\lambda}+\frac{1}{\theta-1} \hat{n}_{t} \\
= & {[1-\lambda \beta(1-\delta)]\left(\widehat{P}_{t}-\frac{a_{2}}{a_{0}} \widehat{m c}_{t}\right) } \\
& +\lambda \beta(1-\delta)\left(\frac{E_{t} \widehat{P}_{t+1}-\lambda \widehat{P}_{t}}{1-\lambda}+\frac{1}{\theta-1} E_{t} \hat{n}_{t+1}\right)
\end{aligned}
$$

Multiplying each side by $1-\lambda$, adding to both sides $\lambda \widehat{P}_{t}$ and simplifying, we obtain:

$$
\begin{aligned}
\lambda\left(\widehat{P}_{t}-\widehat{P}_{t-1}\right)= & \lambda \beta(1-\delta)\left(E_{t} \widehat{P}_{t+1}-\widehat{P}_{t}\right)-(1-\lambda)[1-\lambda \beta(1-\delta)] \frac{a_{2}}{a_{0}} \widehat{m c}_{t} \\
& +\lambda \beta(1-\delta) \frac{1-\lambda}{\theta-1} E_{t} \hat{n}_{t+1}-\frac{1-\lambda}{\theta-1} \hat{n}_{t}
\end{aligned}
$$

We know that $\pi_{t}=\widehat{P}_{t}-\widehat{P}_{t-1}$ and $\pi_{t+1}^{e}=\widehat{P}_{t+1}-\widehat{P}_{t}$. Then, dividing by $\lambda$ and substituting for $\pi_{t}$ and $\pi_{t+1}^{e}$, we reach an expression for inflation:

$$
\begin{aligned}
\pi_{t}= & \beta(1-\delta) E_{t} \pi_{t+1}-\frac{(1-\lambda)[1-\lambda \beta(1-\delta)]}{\lambda} \frac{a_{2}}{a_{0}} \widehat{m c}_{t} \\
& +\frac{\beta(1-\delta)(1-\lambda)}{\theta-1} E_{t} \hat{n}_{t+1}-\frac{(1-\lambda)}{\lambda(\theta-1)} \hat{n}_{t}
\end{aligned}
$$


Using $a_{2} / a_{0}=-(n-1)[\theta(n-1)+1] /[\theta-1+\theta n(n-1)]$ and substituting we finally get the NKPC. When $n$ is exogenous, we impose $\hat{n}_{t+1}=\hat{n}_{t}=0$ and $\delta=0$ which delivers (15), and when $n$ is endogenous we obtain (31).

\section{Rotemberg pricing}

For comparison purposes, let us consider Rotemberg pricing (see also Faia, 2012). In every period $t$, each firm $i$ chooses the price $p_{t}$ to maximize its own value:

$V_{t}=E_{t} \sum_{k=0}^{\infty}(1-\delta)^{k} Q_{t+k}\left\{\left[p_{t+k}(i)-M C_{t+k}\right] C_{t+k}(i)-\frac{\chi}{2}\left(\frac{p_{t+k}(i)}{p_{t+k-1}(i)}-1\right)^{2} p_{t+k}(i) C_{t+k}(i)\right\}$

Its problem can be simplified as follows:

$$
\max _{p_{t}(i)} \frac{\left\{p_{t}(i)\left[1-\frac{\chi}{2}\left(\frac{p_{t}(i)}{p_{t-1}(i)}-1\right)^{2}\right]-M C_{t}\right\} p_{t}(i)^{-\theta}}{\sum_{j=1}^{n_{t}} p_{t}(j)^{1-\theta}}-\frac{(1-\delta) \beta \chi\left(\frac{p_{t+1}(i)}{p_{t}(i)}-1\right)^{2} p_{t+1}(i)^{1-\theta}}{2 \sum_{j=1}^{n_{t}} p_{t+1}(j)^{1-\theta}}
$$

The FOC is:

$$
\begin{gathered}
-(1-\theta)\left(\frac{p_{t}(i)}{P_{t}}\right)^{-\theta} \frac{\left\{p_{t}(i)\left[1-\frac{\chi}{2}\left(\frac{p_{t}(i)}{p_{t-1}(i)}-1\right)^{2}\right]-M C_{t}\right\}}{P_{t}^{2-\theta}}+ \\
+\left[\frac{1-\theta}{P_{t}}+\theta \frac{M C_{t}}{P_{t} p_{t}}-\frac{(1-\theta) \chi}{2 P_{t}}\left(\frac{p_{t}(i)}{p_{t-1}(i)}-1\right)^{2}\right]\left(\frac{p_{t}(i)}{P_{t}}\right)^{-\theta}+ \\
-\frac{\chi}{P_{t}}\left(\frac{p_{t}(i)}{p_{t-1}(i)}-1\right)\left(\frac{p_{t}(i)}{P_{t}}\right)^{-\theta}+\beta(1-\delta) \chi\left(\frac{p_{t+1}(i)}{p_{t}(i)}-1\right)\left(\frac{p_{t+1}(i)}{P_{t+1}}\right)^{1-\theta} \frac{p_{t+1}(i)}{p_{t}^{2}(i)}=0
\end{gathered}
$$

Imposing symmetry, defining the real marginal cost as $m c_{t}=M C_{t} / P_{t}$ and the (gross) producer price inflation as $\Pi_{t}=p_{t} / p_{t-1}$, and finally using $n_{t}=\left(p_{t} / P_{t}\right)^{\theta-1}$, we have:

$$
\begin{gathered}
-(1-\theta) n_{t}^{-1}+(1-\theta) m c_{t} n_{t}^{-\frac{\theta}{\theta-1}}+\frac{(1-\theta) \chi}{2}\left(\Pi_{t}-1\right)^{2} n_{t}^{-1}+1-\theta+\theta m c_{t} n_{t}^{\frac{1}{1-\theta}} \\
-\frac{(1-\theta) \chi}{2}\left(\Pi_{t}-1\right)^{2}-\chi\left(\Pi_{t}-1\right) \Pi_{t}+\beta(1-\delta) \chi\left(E_{t} \Pi_{t+1}-1\right) E_{t}\left\{\Pi_{t+1} \frac{n_{t}}{n_{t+1}}\right\}=0
\end{gathered}
$$

Loglinearizing the FOC provides the producer price inflation rate $\tilde{\pi}_{t}$ as:

$$
\tilde{\pi}_{t}=\beta(1-\delta) E_{t} \tilde{\pi}_{t+1}+\frac{(\theta-1)(n-1)}{\chi n} \widehat{m c}_{t}-\frac{\theta-1+\theta n(n-1)}{\chi n(\theta n-\theta+1)} \hat{n}_{t}
$$

which goes back to the result of Bilbiie et al. (2008) under monopolistic competition (for $n \rightarrow \infty)$. To recover the consumer price inflation $\pi_{t}$, we use $n_{t}=\left(p_{t} / P_{t}\right)^{\theta-1}$ to derive $\tilde{\pi}_{t}=\pi_{t}+\left(\widehat{n}_{t}-\widehat{n}_{t-1}\right) /(\theta-1)$ from which we obtain the final NKPC in the rate of consumer price inflation:

$$
\pi_{t}=\beta(1-\delta) E_{t} \pi_{t+1}+\frac{(\theta-1)(n-1)}{\chi^{n}} \widehat{m c}_{t}+\frac{\beta(1-\delta) E_{t} \widehat{n}_{t+1}+\widehat{n}_{t-1}}{\theta-1}-\varrho(n) \hat{n}_{t}
$$


with:

$$
\varrho(n)=\frac{[\theta-1+\theta n(n-1)](\theta-1)-\chi n(\theta n-\theta+1)[1-\beta(1-\delta)]}{\chi n(\theta n-\theta+1)(\theta-1)}
$$

\section{Appendix B: Full Model with Endogenous Market Structures}

Consider our decentralized economy with endogenous entry of firms. The household maximizes utility choosing how much to work and consume and what to invest in shares of a mutual fund of firms and in a complete contingent claims market. A fraction $s_{t}$ of the mutual fund entitles to receive a corresponding fraction of the dividends of all the firms, whose average value is $V_{t}$. $B_{t}$ denots bond holding and $i_{t}$ is their interest rate. Therefore, the budget constraint expressed in real terms is:

$$
C_{t}+V_{t}\left(n_{t}+n_{t}^{e}\right) s_{t+1}+B_{t}=\left(1+\tau_{t}\right) w_{t} L_{t}+\left(1+i_{t-1}\right) B_{t-1}+\left(\left(1-\tau_{t}^{D}\right) d_{t}+V_{t}\right) n_{t} s_{t}-T_{t}
$$

where $n_{t}$ and $n_{t}^{e}$ are the active firms in period $t$ and the new entrants at the end of the period $w_{t}$ is the wage, $\tau_{t}$ is a labor income subsidy, $\tau_{t}^{D}$ a capital income tax and $T_{t}$ are lump sum taxes needed to finance the subsidy. Households are subject to a borrowing limit $\lim _{s \rightarrow \infty} E_{t}\left(1+i_{s}\right) B_{s} \geq 0$ to avoid Ponzi games. The FOCs are:

$$
\begin{gathered}
L_{t}: \quad \frac{v L_{t}^{\phi}}{C_{t}^{-1}}=\left(1+\tau_{t}\right) w_{t} \\
s_{t+1}: \quad \frac{V_{t}\left(n_{t}+n_{t}^{e}\right)}{C_{t}}=\beta E_{t}\left\{\frac{\left[\left(1-\tau_{t+1}^{D}\right) d_{t+1}+V_{t+1}\right] n_{t+1}}{C_{t+1}}\right\} \\
B_{t}: \quad \frac{E_{t}\left(1+i_{t}\right)}{C_{t} P_{t}}=\beta E_{t}\left[\frac{1}{C_{t+1} P_{t+1}}\right]
\end{gathered}
$$

Labor is the only input, and output of firm $i$ is $y_{t}(i)=A_{t} l_{t}(i)$, where $A_{t}$ is total factor productivity at time $t$, and $l_{t}(i)$ is total labor employed by firm $i$. The real marginal cost is $m c_{t}=w_{t} / A_{t}$. The number of firms active in the representative sector is now variable and follows the equation of motion $n_{t}=(1-\delta)\left(n_{t-1}+n_{t-1}^{e}\right)$, where $\delta \in(0,1)$ is an exogenous exit probability and $n_{t}^{e}$ is the endogenous number of entrants in period $t$. We assume that the creation of a new firm requires a fixed investment of $\eta$ in units of output, so that an increase in productivity affects both the technologies for producing goods and firms. The endogenous entry condition in each period sets $V_{t}=\eta$ as long as $n_{t}^{e}>0$, as we will assume to hold around the steady state. Using all this, we can rewrite the equilibrium conditions as:

$$
\begin{gathered}
\frac{v L_{t}^{\phi}}{C_{t}^{-1}}=\left(1+\tau_{t}\right) m c_{t} A_{t} \\
C_{t}^{-1}=\beta(1-\delta) E_{t}\left[C_{t+1}^{-1}\left(1+\frac{\left(1-\tau_{t+1}^{D}\right) d_{t+1}}{\eta}\right)\right]
\end{gathered}
$$

The resource constraint of the economy is:

$$
Y_{t}=C_{t}+n_{t}^{e} V_{t}=n_{t} d_{t}+w_{t} L_{t}
$$


Since the demand of good $i$ at time $t$ is $y_{t}(i)=\left[p_{t}(i) / P_{t}\right]^{-\theta} Y_{t}$ total production must satisfy:

$$
\sum_{j=1}^{n_{t}} y_{t}(j)=A_{t} \sum_{j=1}^{n_{t}} l_{t}(j)=A_{t} L_{t}=\sum_{j=1}^{n_{t}}\left(\frac{p_{t}(j)}{P_{t}}\right)^{-\theta} Y_{t} \equiv \Delta_{t} Y_{t} \quad \Leftrightarrow \quad Y_{t}=\frac{A_{t} L_{t}}{\Delta_{t}}
$$

where the dispersion aggregator $\Delta_{t}=\sum_{j=1}^{n_{t}}\left[p_{t}(j) / P_{t}\right]^{-\theta}$ depends on both price dispersion and on the number of goods. Notice that with constant producer prices we have $\Delta_{t}=$ $n_{t}^{1 /(1-\theta)}$, which is decreasing in the number of goods: while price dispersion increases the labor needed to produce the composite final good, a higher number of goods available reduces the labor needed for it. Expliciting the expression for the dispersion aggregator we obtain:

$$
\begin{aligned}
\Delta_{t} & =\lambda \frac{n_{t}}{n_{t-1}} \sum_{j=1}^{n_{t-1}}\left(\frac{p_{t-1}(j)}{P_{t}}\right)^{-\theta}+(1-\lambda) n_{t}\left(\frac{p_{t}}{P_{t}}\right)^{-\theta} \\
& =\lambda \frac{n_{t}}{n_{t-1}}\left(1+\pi_{t}\right)^{\theta} \Delta_{t-1}+(1-\lambda) n_{t}\left(\frac{p_{t}}{P_{t}}\right)^{-\theta}
\end{aligned}
$$

The average price index satisfies $P_{t}^{1-\theta}=\lambda P_{t-1}{ }^{1-\theta}+(1-\lambda) n_{t} p_{t}^{1-\theta}$. Dividing both sides by $P_{t}^{1-\theta}$ we have:

$$
1=\lambda\left(1+\pi_{t}\right)^{\theta-1}+(1-\lambda) n_{t}\left(\frac{p_{t}}{P_{t}}\right)^{1-\theta}
$$

Solving for $p_{t} / P_{t}$ and replacing above, we obtain the following equation of motion for the dispersion aggregator (generalizing Yun, 2005):

$$
\Delta_{t}=\lambda \frac{n_{t}}{n_{t-1}}\left(1+\pi_{t}\right)^{\theta} \Delta_{t-1}+\left[(1-\lambda) n_{t}\right]^{\frac{1}{1-\theta}}\left[1-\lambda\left(1+\pi_{t}\right)^{\theta-1}\right]^{\frac{\theta}{\theta-1}}
$$

Using the resource constraint we have $C_{t}+n_{t}^{e} V_{t}=A_{t} L_{t} / \Delta_{t}$, and using the endogenous entry condition and the evolution of the number of firms we have:

$$
C_{t}=\frac{A_{t} L_{t}}{\Delta_{t}}-\eta\left(\frac{n_{t+1}}{1-\delta}-n_{t}\right)
$$

The dynamic model can be summarized with a system of 15 equations:

Consumption Euler Equation:

$$
1: C_{t}^{-1}=\beta E_{t}\left\{\frac{1+i_{t}}{1+\pi_{t+1}} C_{t+1}^{-1}\right\}
$$

Euler equation for $V$ :

$$
2: V_{t}=\beta(1-\delta) E_{t}\left\{\left(\frac{C_{t+1}}{C_{t}}\right)^{-1}\left[V_{t+1}+d_{t+1}\right]\right\}
$$

Entry condition:

$$
3: V_{t}=\eta
$$

Aggregate Resource constraint:

$$
4: C_{t}+n_{t}^{e} V_{t}=n_{t} d_{t}+w_{t} L_{t}
$$


Profits:

$$
5: d_{t}=\frac{Y_{t}-w_{t} L_{t}}{n_{t}}
$$

Law of motion of firms:

$$
6: n_{t}=(1-\delta)\left(n_{t-1}+n_{t}^{e}\right)
$$

Labor market equilibrium:

$$
7: A_{t} m c_{t}=v L_{t}^{\phi} C_{t}
$$

Production function:

$$
8: Y_{t}=\frac{A_{t} L_{t}}{\Delta_{t}}
$$

Relative price:

$$
9: p_{t}^{*}=\frac{p_{t}}{P_{t}}=\left(\frac{1-\lambda\left(1+\pi_{t}\right)^{\theta-1}}{(1-\lambda) n_{t}}\right)^{\frac{1}{1-\theta}}
$$

Price setting equation:

$$
10: p_{t}^{*} F_{t}=K_{t}+\left(p_{t}^{*}\right)^{2-\theta} G_{t}-\left(p_{t}^{*}\right)^{1-\theta} H_{t}
$$

where $F_{t}, K_{t}, G_{t}$ and $H_{t}$ can be written in recursive form as:

$$
\begin{gathered}
11: F_{t}=1+\lambda \beta E_{t}\left\{\left(1+\pi_{t+1}\right)^{\theta-1} F_{t+1}\right\}, \\
12: K_{t}=\frac{\theta}{\theta-1} m c_{t}+\lambda \beta E_{t}\left\{\left(1+\pi_{t+1}\right)^{\theta} K_{t+1}\right\}, \\
13: G_{t}=1+\lambda \beta E_{t}\left\{\left(1+\pi_{t+1}\right)^{2(\theta-1)} G_{t+1}\right\}, \\
14: H_{t}=m c_{t}+\lambda \beta E_{t}\left\{\left(1+\pi_{t+1}\right)^{2 \theta-1} H_{t+1}\right\}
\end{gathered}
$$

Price dispersion:

$$
15: \Delta_{t}=\lambda \frac{n_{t}}{n_{t-1}}\left(1+\pi_{t}\right)^{\theta} \Delta_{t-1}+\left(1-\lambda\left(1+\pi_{t}\right)^{\theta-1}\right)\left(p_{t}^{*}\right)^{-1}
$$

plus a monetary policy rule.

\section{Log-linearization}

The equilibrium can be log-linearized in the following equations:

$$
\begin{gathered}
\hat{C}_{t}=E_{t} \hat{C}_{t+1}-\left(\hat{\imath}_{t}-E_{t} \pi_{t+1}\right) \\
\hat{V}_{t}=\beta(1-\delta) E_{t} \hat{V}_{t+1}+\beta(1-\delta) \frac{d}{V} E_{t} \widehat{d}_{t+1}-\left(E_{t} \widehat{C}_{t+1}-\widehat{C}_{t}\right) \\
\widehat{V}_{t}=0 \\
\widehat{C}_{t}+\frac{n^{e} V}{C} \widehat{n}_{t}^{e}+\frac{n^{e} V}{C} \widehat{V}_{t}=\frac{n d}{C} \widehat{n}_{t}+\frac{n d}{C} \widehat{d}_{t}+\frac{w L}{C} \widehat{w}_{t}+\frac{w L}{C} \widehat{L}_{t} \\
\widehat{d}_{t}+\widehat{n}_{t}=\frac{y}{d n} y_{t}-\frac{w L}{d n} \widehat{w}_{t}-\frac{w L}{d n} \widehat{L}_{t}
\end{gathered}
$$




$$
\begin{gathered}
\hat{n}_{t+1}=(1-\delta) \hat{n}_{t}+\delta \hat{n}_{t}^{e} \\
\widehat{w}_{t}=\widehat{C}_{t}+\phi \widehat{L}_{t} \\
\widehat{w}_{t}=\widehat{A}_{t}+\widehat{m c}_{t} \\
\widehat{y}_{t}=\widehat{A}_{t}+\widehat{L}_{t}+\frac{\widehat{n}_{t}}{\theta-1}
\end{gathered}
$$

plus the monetary rule and the appropriate NKPC. To solve for the steady state, notice that:

$$
m c=\frac{(\theta-1)(n-1)}{\theta n-\theta+1} n^{\frac{1}{\theta-1}}
$$

Fixing $A$ and $\eta$, we have $V=\eta$ and consequently $d=\eta(1-\beta(1-\delta)) / \beta(1-\delta)$. Moreover, we have output $y=A L n^{\frac{1}{\theta-1}}$, wage $w=m c A$, and consumption $C=m c A / v L^{\phi}$. Using these in the steady state system we obtain a relation between number of firms and labor demand:

$$
L(n)=n \eta \frac{(1-\beta(1-\delta))}{\beta(1-\delta)}\left(n^{\frac{1}{\theta-1}} A\left(1-\frac{(\theta-1)(n-1)}{\theta n-\theta+1}\right)\right)^{-1}
$$

and a single equation for $n$, that is:

$$
\frac{(\theta-1)(n-1)}{\theta n-\theta+1} n^{\frac{2-\theta}{\theta-1}} \frac{A}{v} L(n)^{-\phi}+\frac{\delta \eta}{1-\delta}=\frac{\eta(1-\beta(1-\delta))}{\beta(1-\delta)}+\frac{(\theta-1)(n-1)}{\theta n-\theta+1} n^{\frac{2-\theta}{\theta-1}} A=0
$$

From the latter we derive $n$ and, accordingly, $L(n)$ and all the other steady state variables.

\section{Optimal monetary policy with subsidies}

The social planner problem under flexible prices is obtained using the resource constraint with $\Delta_{t}=n_{t}^{1 /(1-\theta)}$ :

$$
\begin{array}{r}
\max _{L_{t}, n_{t+1}} E_{0} \sum_{t=0}^{\infty} \beta^{t}\left(\log C_{t}-\frac{v L_{t}^{1+\phi}}{1+\phi}\right) \\
\text { s.v. } \quad C_{t}=A_{t} L_{t} n_{t}^{\frac{1}{\theta-1}}-\eta\left(\frac{n_{t+1}}{1-\delta}-n_{t}\right)
\end{array}
$$

The FOCs are:

$$
\begin{gathered}
L_{t}: \quad \frac{v L_{t}^{\phi}}{C_{t}^{-1}}=A_{t} n_{t}^{\frac{1}{\theta-1}} \\
n_{t+1}: \quad C_{t}^{-1}=\beta(1-\delta) E_{t} C_{t+1}^{-1}\left[1+\frac{A_{t+1} L_{t+1} n_{t+1}^{\frac{2-\theta}{\theta-1}}}{\eta(\theta-1)}\right]
\end{gathered}
$$

This allocation can be reproduced with zero producer price inflation, which involves the following consumer price inflation rate:

$$
\pi_{t}^{*}=\left(\frac{n_{t}}{n_{t-1}}\right)^{\frac{1}{1-\theta}}-1
$$

In this case, all firms adopt always a constant price corresponding to the equilibrium price under flexible prices:

$$
p=\frac{\theta n_{t}-\theta+1}{(\theta-1)\left(n_{t}-1\right)} \frac{W_{t}}{A_{t}}
$$


Diving by $P_{t}$ both sides allows to derive the marginal cost:

$$
m c_{t}=\frac{(\theta-1)\left(n_{t}-1\right)}{\theta n_{t}-\theta+1} n_{t}^{\frac{1}{\theta-1}}
$$

Since optimality requires that the right hand sides of (58) and (77) are equal, $\left(1+\tau_{t}\right) m c_{t} A_{t}=$ $A_{t} n_{t}^{\frac{1}{\theta-1}}$, the optimal labor subsidy must be:

$$
\tau_{t}^{*}=\frac{n_{t}}{(\theta-1)\left(n_{t}-1\right)}
$$

which is always positive and allows one to verify that $p=n_{t}^{\frac{1}{\theta-1}} P_{t}$ is always constant. The subsidy is decreasing in the elasticity of substitution and in the number of firms. Since $w_{t} L_{t}=m c_{t} A_{t} L_{t}=A_{t} L_{t} n_{t}^{\frac{1}{\theta-1}} /\left(1+\tau_{t}^{*}\right)$ dividends are:

$$
d_{t}=\frac{Y_{t}-w_{t} L_{t}}{n_{t}}=\frac{A_{t} L_{t} n_{t}^{\frac{2-\theta}{\theta-1}} \tau_{t}^{*}}{1+\tau_{t}^{*}}
$$

Since optimality requires that the right hand sides of (59) and (78) are equal in each period, we need to have $\left(1-\tau_{t}^{D}\right) \tau_{t}^{*}(\theta-1)=1+\tau_{t}^{*}$, or:

$$
\tau_{t}^{* D}=\frac{\theta-1-n_{t}}{n_{t}(\theta-1)}
$$

which is negative only if the number of firms is large enough: notice that with monopolistic competition $\tau_{t}^{*}=-\tau_{t}^{* D}=1 /(\theta-1)$. The case we are interested in, with a small number of firms and high elasticity of substitution, delivers a positive and countercyclical dividend taxation.

\section{The Ramsey problem}

We now compute the modified golden rule steady state inflation. This is obtained by imposing steady state conditions ex post on the first order conditions of the Ramsey plan. The Ramsey optimal plan is determined by maximizing the discounted sum of utilities of all agents given the constraints of the competitive economy and assuming that ex-ante commitment is feasible. As it is in most NK models it is not possible to combine all equations of the competitive equilibrium in a single implementability constraint, thus we follow an hybrid approach in which the competitive equilibrium conditions are summarized via a minimal set of equations, as reported below. In this context, the central bank chooses the policy instrument, namely the inflation rate, to implement the optimal allocation obtained as solution to the Ramsey problem.

We now reduce the 15 equilibrium conditions to a smaller number. First of all, notice that the equation of the instrument $i_{t}$, i.e. the Euler equation for bonds is not necessary. This comes from the fact that the nominal interest rate enters only into the Euler equation for bonds. Then, once the Central Bank has choosen the optimal path for $C_{t}$ and $\pi_{t}$ (using all the other constraints) the nominal interest rate is determined ex-post. As for the standard NK model, the Lagrangean multiplier associated with the Euler equation for bonds is always zero. This means that we are left with 14 equations. We then combine all the static equations with the eight dynamic ones, i.e the law of motion of $n_{t}$, the equation for the optimal price, the price dispersion equation and the Euler equation for firms shares, plus the 4 auxiliary 
variables $F_{t}, K_{t}, G_{t}$ and $H_{t}$. In particular, using the resource constraint and substituting for the equation of firms profits, we have:

$$
\begin{aligned}
C_{t}+n_{t}^{e} V_{t} & =n_{t} d_{t}+w_{t} L_{t} \\
& =Y_{t}-w_{t} L_{t}+w_{t} L_{t} \\
& =\frac{A_{t} L_{t}}{\Delta_{t}}
\end{aligned}
$$

where we used that $Y_{t}=\frac{A_{t} L_{t}}{\Delta_{t}}$. Combing now the endogenous entry condition and the equation of evolution of the number of firms we get:

$$
C_{t}+\eta\left(\frac{n_{t+1}}{1-\delta}-n_{t}\right)=\frac{A_{t} L_{t}}{\Delta_{t}}
$$

substituting into the previos the labor market equilibrium equation solved for $C_{t}$, that is $C_{t}=\frac{L_{t}^{-\phi} A_{t} m c_{t}}{v}$, we find the first constraint of the Ramsey problem, which is:

$$
(1 R): \frac{A_{t} m c_{t}}{v}+\eta\left(\frac{n_{t+1}}{1-\delta}-n_{t}\right) L_{t}^{\phi}=\frac{A_{t} L_{t}^{1+\phi}}{\Delta_{t}} .
$$

Then, considering

$$
C_{t}^{-1}=\beta(1-\delta) E_{t}\left[C_{t+1}^{-1}\left(1+\frac{d_{t+1}}{\eta}\right)\right]
$$

and substituting for $C_{t}=\frac{L_{t}^{-\phi} A_{t} m c_{t}}{v}$ and $C_{t+1}=\frac{L_{t+1}^{-\phi} A_{t+1} m c_{t+1}}{v}$,

$$
\left(\frac{L_{t}^{-\phi} A_{t} m c_{t}}{v}\right)^{-1}=\beta(1-\delta) E_{t}\left[\left(\frac{L_{t+1}^{-\phi} A_{t+1} m c_{t+1}}{v}\right)^{-1}\left(1+\frac{d_{t+1}}{\eta}\right)\right]
$$

substituting profits $d_{t}=\frac{A_{t} L_{t}}{n_{t} \Delta_{t}}-\frac{A_{t} m c_{t} L_{t}}{n_{t}}$, into Euler above, we find the second constraint of the Ramsey problem:

$$
\begin{aligned}
(2 R) & :\left(\frac{L_{t}^{-\phi} A_{t} m c_{t}}{v}\right)^{-1} \\
= & \beta(1-\delta) E_{t}\left[\begin{array}{l}
\left(\frac{L_{t+1}^{-\phi} A_{t+1} m c_{t+1}}{v}\right)^{-1} \\
\left.\left(1+\frac{1}{\eta n_{t+1}}\left(\frac{A_{t+1} L_{t+1}}{\Delta_{t+1}}-A_{t+1} m c_{t+1} L_{t+1}\right)\right)\right]
\end{array}\right.
\end{aligned}
$$

the third and the fourth constraints come from the equation of price dispersion and that of the optimal price, respectively:

$$
(3 R): \Delta_{t}=\Delta_{t}=\lambda \frac{n_{t}}{n_{t-1}}\left(1+\pi_{t}\right)^{\theta} \Delta_{t-1}+\left(1-\lambda\left(1+\pi_{t}\right)^{\theta-1}\right)\left(p_{t}^{*}\right)^{-1}
$$

and

$$
(4 R): p_{t}^{*} F_{t}=K_{t}+\left(p_{t}^{*}\right)^{2-\theta} G_{t}-p_{t}^{1-\theta} H_{t}
$$


where $p_{t}^{*}$ is the relative price, that is $p_{t}^{*} \equiv \frac{p_{t}}{P_{t}}$. We then rewrite the four auxiliary variables $F_{t}, K_{t}, G_{t}$ and $H_{t}$ in recursive form, that is:

$$
\begin{gathered}
(5 R): F_{t}=1+\lambda \beta E_{t}\left\{\left(1+\pi_{t+1}\right)^{\theta-1} F_{t+1}\right\}, \\
(6 R): K_{t}=\frac{\theta}{\theta-1} m c_{t}+\lambda \beta E_{t}\left\{\left(1+\pi_{t+1}\right)^{\theta} K_{t+1}\right\}, \\
(7 R): G_{t}=1+\lambda \beta E_{t}\left\{\left(1+\pi_{t+1}\right)^{2(\theta-1)} G_{t+1}\right\},
\end{gathered}
$$

and

$$
(8 R): H_{t}=m c_{t}+\lambda \beta E_{t}\left\{\left(1+\pi_{t+1}\right)^{2 \theta-1} H_{t+1}\right\}
$$

Finally, to easily derive the proof on the Ramsey optimal steady state we do not substitute the equation for the relative price $p_{t}^{*}$, which becomes the ninth Ramey constraint, i.e.:

$$
(9 R): p_{t}^{*}=\left(\frac{1-\lambda\left(1+\pi_{t}\right)^{\theta-1}}{(1-\lambda) n_{t}}\right)^{\frac{1}{1-\theta}}
$$

The Ramsey problem consists of maximizing the households utility function subject to the 9 constraints, $(1 R)-(9 R)$. Thus, the Ramsey problem can be written as follows:

$$
\begin{aligned}
& \max _{\left\{L_{t}, \pi_{t}, \Delta_{t}, n_{t+1}, m c_{t}, F_{t}, K_{t}, G_{t}, H_{t}, p_{t}^{*}\right\}} E_{0} \sum_{t=0}^{\infty} \beta^{t}\left(\log \left[\frac{A_{t} L_{t}}{\Delta_{t}}-\eta\left(\frac{n_{t+1}}{1-\delta}-n_{t}\right)\right]-\frac{v L_{t}^{1+\phi}}{1+\phi}\right) \\
& \text { s.t. }(1 R)-(9 R)
\end{aligned}
$$

where we have already substituted $C_{t}=\frac{A_{t} L_{t}}{\Delta_{t}}-\eta\left(\frac{n_{t+1}}{1-\delta}-n_{t}\right)$ into the utility function. We define the 9 Lagrangean multipliers $\mu_{1, t}, \mu_{2, t}, \mu_{3, t}, \mu_{4, t}, \mu_{5, t}, \mu_{6, t}, \mu_{7, t}, \mu_{8, t}, \mu_{8}, \mu_{9}$ each one associated to one of the 9 constraints. To compute the modified golden rule steady state inflation, we first derive the first order conditions of the Ramsey plan, we then impose the steady state. Then, starting from a guess on the value of the steady state inflation rate, we verify if our guess is a solution of the Ramsey plan. The FOCs that solve the Lagrangean are:

$$
\begin{aligned}
L_{t} \quad: \quad 0=\frac{1}{C_{t}} \frac{A_{t}}{\Delta_{t}}-v L_{t}^{\phi}+\mu_{1, t}\left(\phi \eta\left(\frac{n_{t+1}}{1-\delta}-n_{t}\right) L_{t}^{\phi-1}-(1+\phi) \frac{A_{t} L_{t}^{\phi}}{\Delta_{t}}\right)+ \\
+\mu_{2, t} \phi\left(\frac{L_{t}^{-\phi} A_{t} m c_{t}}{v}\right)^{-2} \frac{L_{t}^{-\phi-1} A_{t} m c_{t}}{v}+ \\
\quad \mu_{2, t-1} \frac{1}{\beta}\left(\begin{array}{c}
-\phi \beta(1-\delta)\left(\frac{L_{t}^{-\phi} A_{t} m c_{t}}{v}\right)^{-2} \frac{L_{t}^{-\phi-1} A_{t} m c_{t}}{v} \cdot \\
\cdot\left(1+\frac{1}{\eta n_{t}}\left(\frac{A_{t} L_{t}}{\Delta_{t}}-A_{t} m c_{t} L_{t}\right)\right)
\end{array}\right)+ \\
\quad-\mu_{2, t-1} \frac{1}{\beta}\left(\beta(1-\delta)\left(\frac{L_{t}^{-\phi} A_{t} m c_{t}}{v}\right)^{-1}\left(\frac{1}{\eta n_{t}}\left(\frac{A_{t}}{\Delta_{t}}-A_{t} m c_{t}\right)\right)\right)
\end{aligned}
$$




$$
\begin{aligned}
& \pi_{t} \quad: \quad 0=-\mu_{3, t} \lambda \frac{n_{t}}{n_{t-1}} \theta\left(1+\pi_{t}\right)^{\theta-1} \Delta_{t-1}+\mu_{3, t}(\theta-1) \lambda\left(1+\pi_{t}\right)^{\theta-2}\left(p_{t}^{*}\right)^{-1} \\
& -\mu_{5, t-1} \beta^{-1}(\theta-1) \lambda \beta\left(1+\pi_{t}\right)^{\theta-2} F_{t}-\mu_{6, t-1} \beta^{-1} \theta \lambda \beta\left(1+\pi_{t}\right)^{\theta-1} K_{t}+ \\
& -\mu_{7, t-1} \beta^{-1} 2(\theta-1) \lambda \beta\left(1+\pi_{t}\right)^{2(\theta-1)-1} G_{t}-\mu_{8, t} \beta^{-1} \lambda \beta(2 \theta-1)\left(1+\pi_{t}\right)^{2 \theta-2} H_{t} \\
& -\mu_{9, t}\left(\frac{1-\lambda\left(1+\pi_{t}\right)^{\theta-1}}{(1-\lambda) n_{t}}\right)^{\frac{\theta}{1-\theta}}\left(\frac{\lambda\left(1+\pi_{t}\right)^{\theta-2}}{(1-\lambda) n_{t}}\right) \\
& \Delta_{t} \quad: \quad 0=-\frac{1}{C_{t}} \frac{A_{t} L_{t}}{\Delta_{t}^{2}}+\mu_{1, t} \frac{A_{t} L_{t}^{1+\phi}}{\Delta_{t}^{2}}+ \\
& -\mu_{2, t-1} \beta^{-1} \beta(1-\delta)\left(\frac{L_{t}^{-\phi} A_{t} m c_{t}}{v}\right)^{-1}\left(\frac{1}{\eta} \frac{A_{t} L_{t}}{n_{t} \Delta_{t}^{2}}\right)+ \\
& +\mu_{3, t}-\mu_{3, t+1} \beta \lambda \frac{n_{t+1}}{n_{t}}\left(1+\pi_{t+1}\right)^{\theta} \\
& n_{t+1} \quad: \quad 0=-\frac{\eta}{1-\delta} \frac{1}{C_{t}}+\beta \frac{1}{C_{t+1}} \eta+ \\
& -\mu_{1, t+1} \beta \eta L_{t+1}^{\phi}+\mu_{1, t} \frac{\eta}{1-\delta} L_{t}^{\phi}+ \\
& -\mu_{2, t} \beta(1-\delta)\left[\begin{array}{c}
\left(\frac{L_{t+1}^{-\phi} A_{t+1} m c_{t+1}}{v}\right)^{-1} \cdot \\
\cdot \frac{1}{\eta n_{t+1}^{2}}\left(\frac{A_{t+1} L_{t+1}}{\Delta_{t+1}}-A_{t+1} m c_{t+1} L_{t+1}\right)
\end{array}\right]+ \\
& +\mu_{3, t+1} \beta\left(-\lambda \frac{1}{n_{t}}\left(1+\pi_{t+1}\right)^{\theta} \Delta_{t}\right)+ \\
& +\mu_{3, t+2} \beta^{2} \lambda \frac{n_{t+2}}{n_{t+1}^{2}}\left(1+\pi_{t+2}\right)^{\theta} \Delta_{t+2} \\
& m c_{t} \quad: \quad 0=\mu_{1, t} \frac{A_{t}}{v}-\mu_{2, t}\left(\frac{L_{t}^{-\phi} A_{t} m c_{t}}{v}\right)^{-2} \frac{L_{t}^{-\phi} A_{t}}{v}+ \\
& +\beta(1-\delta) \mu_{2, t-1} \beta^{-1}\left[\begin{array}{c}
\left(\frac{L_{t}^{-\phi} A_{t} m c_{t}}{v}\right)^{-2} \frac{L_{t}^{-\phi} A_{t}}{v} . \\
\cdot\left(1+\frac{1}{\eta n_{t}}\left(\frac{A_{t} L_{t}}{\Delta_{t}}-A_{t} m c_{t} L_{t}\right)\right)
\end{array}\right]+ \\
& +\beta(1-\delta) \mu_{2, t-1} \beta^{-1}\left(\frac{L_{t}^{-\phi} A_{t} m c_{t}}{v}\right)^{-1} \frac{1}{\eta n_{t}} A_{t} L_{t}+ \\
& -\mu_{6, t} \frac{\theta}{\theta-1}-\mu_{8, t} \\
& F_{t}: \mu_{4, t} p_{t}^{*}+\mu_{5, t}-\mu_{5, t-1} \beta^{-1} \lambda \beta\left(1+\pi_{t}\right)^{\theta-1}=0 \\
& K_{t}:-\mu_{4, t}+\mu_{6, t}-\mu_{6, t-1} \beta^{-1} \beta \lambda\left(1+\pi_{t}\right)^{\theta}=0 \\
& G_{t}:-\mu_{4, t}\left(p_{t}^{*}\right)^{2-\theta}+\mu_{7, t}-\mu_{7, t-1} \beta^{-1} \lambda \beta\left(1+\pi_{t}\right)^{2(\theta-1)}=0
\end{aligned}
$$




$$
\begin{aligned}
H_{t}: & \mu_{4, t}\left(p_{t}^{*}\right)^{1-\theta}+\mu_{8, t}-\mu_{8, t-1} \beta^{-1} \lambda \beta\left(1+\pi_{t}\right)^{2 \theta-1}=0 \\
p_{t}^{*} \quad: \quad & 0=\mu_{3, t}\left(1-\lambda\left(1+\pi_{t}\right)^{\theta-1}\right)\left(p_{t}^{*}\right)^{-2}+\mu_{9, t} \\
& +\mu_{4, t}\left(F_{t}-(2-\theta)\left(p_{t}^{*}\right)^{1-\theta} G_{t}+(1-\theta)\left(p_{t}^{*}\right)^{-\theta} H_{t}\right)
\end{aligned}
$$

The 10 FOCs together with the 9 constraints associated to the 9 lagrangean multipliers define a system of 19 equations in 19 unknowns.

Following Schmidt-Grohe and Uribe (2011), we impose the steady state using the guess of $\pi=0$ and we verify if our guess is a solution of the system, that is if zero inflation steady state is the Ramsey optimal steady state inflation rate. Notice that with $\pi=0$, the steady state of the Ramsey becomes:

$$
\begin{aligned}
& 0=\frac{1}{C} \frac{A}{\Delta}-v L^{\phi}+\mu_{1}\left(\phi \eta\left(\frac{\delta n}{1-\delta}\right) L^{\phi-1}-(1+\phi) \frac{A L^{\phi}}{\Delta}\right) \\
& +\mu_{2} \phi\left(\frac{L^{-\phi} A m c}{v}\right)^{-2} \frac{L^{-\phi-1} A m c}{v} \\
& +\mu_{2}\left(-\phi(1-\delta)\left(\frac{L^{-\phi} A m c}{v}\right)^{-2} \frac{L^{-\phi-1} A m c}{v}\left(1+\frac{1}{\eta n}\left(\frac{A L}{\Delta}-A m c L\right)\right)\right)+ \\
& -\mu_{2}\left((1-\delta)\left(\frac{L^{-\phi} A m c}{v}\right)^{-1}\left(\frac{1}{\eta n} A\left(\frac{1}{\Delta}-m c\right)\right)\right) \\
& 0=-\mu_{3} \lambda \theta \Delta+\mu_{3}(\theta-1) \lambda\left(p^{*}\right)^{-1}-\mu_{5}(\theta-1) \lambda F \\
& -\mu_{6} \theta \lambda K-\mu_{7} 2(\theta-1) \lambda G-\mu_{8} \lambda(2 \theta-1) H-\mu_{9} \frac{\lambda}{(1-\lambda)} n^{\frac{1}{\theta-1}} \\
& 0=-\frac{1}{C} \frac{A L}{\Delta^{2}}+\mu_{1} \frac{A L^{1+\phi}}{\Delta^{2}}+\mu_{3}(1-\beta \lambda) \\
& -\mu_{2}(1-\delta)\left(\frac{L^{-\phi} A m c}{v}\right)^{-1}\left(\frac{1}{\eta} \frac{A L}{n \Delta^{2}}\right) \\
& 0=-\frac{\eta}{1-\delta} \frac{1}{C}+\beta \frac{1}{C} \eta-\mu_{1} \beta \eta L^{\phi}+\mu_{1} \frac{\eta}{1-\delta} L^{\phi}+\mu_{3} \beta^{2} \lambda \frac{1}{n} \Delta \\
& -\mu_{2} \beta(1-\delta)\left(\frac{L^{-\phi} A m c}{v}\right)^{-1} \frac{A L}{\eta n^{2}}\left(\frac{1}{\Delta}-m c\right)-\mu_{3} \beta\left(\lambda \frac{1}{n} \Delta\right) \\
& 0=\mu_{1} \frac{A}{v}-\mu_{2}\left(\frac{L^{-\phi} A m c}{v}\right)^{-2} \frac{L^{-\phi} A}{v}+(1-\delta) \mu_{2}\left(\frac{L_{t}^{-\phi} A_{t} m c_{t}}{v}\right)^{-1} \frac{A L}{\eta n} \\
& (1-\delta) \mu_{2}\left(\frac{L^{-\phi} A m c}{v}\right)^{-2} \frac{L^{-\phi} A}{v}\left(1+\frac{A L}{\eta n}\left(\frac{1}{\Delta}-m c\right)\right)-\mu_{6} \frac{\theta}{\theta-1}-\mu_{8}
\end{aligned}
$$




$$
\begin{gathered}
\mu_{4}=-\mu_{5} \frac{(1-\lambda)}{p^{*}} \\
\mu_{4}=\mu_{6}(1-\lambda) \\
\mu_{4}=\frac{\mu_{7}(1-\lambda)}{p^{* 2-\theta}} \\
\mu_{4}=-\frac{\mu_{8}(1-\lambda)}{p^{* 1-\theta}} \\
\mu_{3}(1-\lambda)\left(p_{t}^{*}\right)^{-2}+\mu_{4}\left(F-(2-\theta)\left(p^{*}\right)^{1-\theta} G+(1-\theta)\left(p^{*}\right)^{-\theta} H\right)+\mu_{9}=0 \\
\frac{A_{t} m c}{v}+\eta \frac{\delta n}{1-\delta} L^{\phi}-\frac{A L^{1+\phi}}{\Delta}=0 \\
1-\beta(1-\delta)\left(1+\frac{A L}{\eta n}\left(\frac{1}{\Delta}-m c\right)\right)=0 \\
\Delta=\left(p^{*}\right)^{-1} \\
p^{*} F-K-\left(p^{*}\right)^{2-\theta} G+\left(p^{*}\right)^{1-\theta} H=0 \\
F=\frac{1}{1-\lambda \beta} \\
\begin{array}{c}
m=\frac{m c}{\theta-1} \\
\left(\frac{m \beta}{1-\lambda \beta}=\frac{\theta}{\theta-1} m c F\right. \\
G=F \\
H=\frac{m c}{1-\lambda \beta}=F m c \\
p^{*}=n^{\frac{1}{\theta-1}}
\end{array}
\end{gathered}
$$

Notice that, once we have given a guess for $\pi=0$ the steady state system becomes a system of 19 equations and 18 unknows:

$$
\left\{p^{*}, F, G, H, K, m c, \Delta, L, n, \mu_{1}, \mu_{2}, \mu_{3}, \mu_{4}, \mu_{5}, \mu_{6}, \mu_{7}, \mu_{8}, \mu_{9}\right\}
$$

As shown by Schmitt-Grohe and Uribe (2011), in order to verify that zero inflation is indeed a solution, we should find that an equation is redundant. After some algebra, we can show that the FOCs with respect to $\pi$ and $p^{*}$, that is equations (92) and (100) are identical. Indeed notice that using (96)-(99) equation (92) can be rewritten as follows:

$-\mu_{3}\left(p^{*}\right)^{-1}(1-\lambda)+\mu_{4}\left(p^{*}(\theta-1) F-\theta K-\left(p^{*}\right)^{2-\theta} 2(\theta-1) F+\left(p^{*}\right)^{1-\theta}(2 \theta-1) H\right)-\mu_{9} p^{*}=0$

Further, using (104) together with (107) rearranging and simplifying, (??) becomes:

$$
-\mu_{3}\left(p^{*}\right)^{-1}(1-\lambda)-\mu_{4}\left(p^{*} F+\left(p^{*}\right)^{2-\theta} 2 F+\left(p^{*}\right)^{2-\theta} \theta F+\left(p^{*}\right)^{1-\theta}(1-\theta) H\right)-\mu_{9} p^{*}=0
$$

Finally, multiplying equation (100) by $\left(-p_{t}^{*}\right)$, it coincides with (111). Thus, one of the two equations is redundant and $\pi=0$ is a solution of the steady state system. 